Canadian

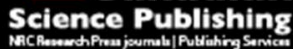

Canadian Geotechnical Journal Revue canadienne de géotechnique

\title{
Phreatic Line Calculation and Stability Analysis of Slopes under the Combined Effect of Reservoir Water Level Fluctuations and Rainfall
}

\begin{tabular}{|r|l|}
\hline Journal: & Canadian Geotechnical Journal \\
\hline Manuscript ID & cgj-2016-0315.R1 \\
\hline Manuscript Type: & Article \\
\hline Complete List of Authors: & $\begin{array}{l}\text { Sun, Guan Hua; State Key Laboratory of Geomechanics and Geotechnical } \\
\text { Engineering, } \\
\text { Yang, Yongtao; Institute of Rock and Soil Mechanics,CAS, } \\
\text { Cheng, Shengguo; China Three Gorges University, College of Civil } \\
\text { Engineering \& Architecture } \\
\text { Zheng, Hong; Chinese Academy of Sciences, }\end{array}$ \\
\hline Keyword: & \begin{tabular}{l} 
slope, landslide, phreatic line, reservoir water level fluctuations, rainfall \\
\hline
\end{tabular} \\
\hline
\end{tabular}

SCHOLARONE ${ }^{\text {M }}$

Manuscripts 


\title{
Phreatic Line Calculation and Stability Analysis of Slopes under the Combined Effect of Reservoir Water Level Fluctuations and Rainfall
}

\author{
Guanhua Sun, Yongtao Yang, Shengguo Cheng, Hong Zheng ${ }^{1}$
}

\begin{abstract}
Rainfall and reservoir water level fluctuations are the main external factors of landslides in the Three Gorges Reservoir area. In order to improve the analysis of slope stability under the combined effect of reservoir water level fluctuations and rainfall, a simplified method for phreatic line calculation of slopes is proposed in this study. Based on the obtained phreatic line, the expression of normal stress on the sliding surface of the slope under the hydrodynamic forces is deduced, and a global analysis method to solve the slope safety factor under hydrodynamic force is proposed. Finally, the safety evolution of a slope in the Three Gorges Reservoir area is studied under the combined effect of reservoir water level fluctuations and rainfall.
\end{abstract}

Key words: slope, landslide, phreatic line, reservoir water level fluctuations, rainfall

\section{Introduction}

From the previous literatures on the landslides, rainfall is a main triggering factor to induce landslides in the Three Gorges Reservoir area (Yin et al. 2012; Sun et al. $2016 a$ ). With the construction of the Three Gorges project and the normal operation of the reservoir after impoundment, the changes of reservoir water level will become another leading factor to induce reservoir slope sliding along with the rainfall (Chen et al. 2003; Yin et al. 2012; Sun et al. 2016a 2016b). Therefore, rainfall and reservoir water level fluctuations are the main driving factors for the recurrence of the ancient

\footnotetext{
${ }^{1}$ Reseived 10 June, 2016

G. Sun, Y. Yang, H. Zheng. State Key Laboratory of Geomechanics and Geotechnical Engineering, Institute of Rock and Soil Mechanics, Chinese Academy of Sciences, Wuhan, Hubei 430071, China.

S. Cheng. College of Civil Engineering \& Architecture, China Three Gorges University, Yichang 443002, China.

Corresponding author: Yongtao Yang (e-mail: scuhhc@126.com).
} 
landslides in the Three Gorges Reservoir area. Especially after the impoundment of the Three Gorges Reservoir, the occurrence of Qianjiangping landslide on July 13, 2003, in which 14 people were dead and 10 were missing, urged people to think about this important issue (Wang et al. 2004 2008; Yin et al. 2015; Xiao et al. 2010a 2010b; Yin et al. 2015; Wang et al. 2016).

In the Three Gorges Reservoir area, many landslide masses that could recur during the reservoir water level fluctuations have been discovered. In the survey and design review of the landslide engineering of the Three Gorges Reservoir, some problems have been identified that need to be clarified and solved: 1) The determination of phreatic line is lack of evidence under the condition of reservoir water level fluctuation; 2) The determination of phreatic line under the condition of rainfall is optional. These two points are related to the soil seepage and the decline of reservoir water level (most unfavorable) that often lead to landslides. 3) The evolution of slope stability under the combined effects of reservoir water level fluctuations and rainfall are the crucial factors for the power generation and flood control of the Three Gorges Dam.

The determination of phreatic line is a free-surface (unconfined) seepage problem in geomechanics. In the free-surface seepage problems, the key point is the determination of the free-surface that delimits the flow boundaries. It can be calculated using the nonlinear numerical techniques such as finite difference method with adaptive mesh (Cryer 1970), finite element method with adaptive mesh (Taylor and Brown 1967; Finn 1967; Neuman and Witherspoon 1970) and fixed mesh (Baiocchi 1972; Bathe and Khoshgoftaar 1979; Kikuchi 1977; Alt 1980; Oden and Kikuchi 1980; Friedman 1982; Desai and Li 1983; Baiocchi and Capello 1984; Westbrook 1985). There has been a good progress in methods for determining the phreatic line of the slope, especially in the numerical analysis methods such as finite difference and finite element methods (Brezis et al. 1978; Zheng et al. 2005; Chen et al. 2008; Ji et al. 2005). However, these numerical methods are not commonly used in engineering practices and largely ignored in soil mechanics textbooks, as they require very complex derivatives and complicated implementations. Therefore, there is a 
requirement to develop a simple and efficient procedure for practical engineering and educational training purposes.

In engineering practices, changes in the groundwater and slope stability are usually presented using uncoupled approaches (Dong et al. 2016; Mohammad et al. 2015). Specifically, the pore water pressure within the slope due to groundwater level variations is first determined, which is used to estimate the resulting pore water pressures at the potential failure surface. The estimated pore water pressure are used in a limit equilibrium analysis for assessing the slope stability conditions in terms of a safety factor defined as the ratio of the soil shear strength available along the failure surface to that of mobilized along the failure surface. In this context, Van Asch and Buma (1997) proposed a one-dimensional hydrological model to describe groundwater fluctuations in relation to precipitation. The model is based on limit equilibrium method to assess the temporal frequency of instability of a landslide. Conte and Troncone (2012a) developed a simplified analytical solution that utilizes the infinite slope model to assess slope stability. The model evaluates the changes in pore pressure on the slip surface using the piezometric measurements. However, the limit equilibrium method is in principle unable to analyze the active landslides for which a realistic prediction of the displacement is required rather than a calculation of the safety factor. Owing to this drawback, Calvello et al. (2008) proposed an empirical relationship for the displacement rate measured at selected points of the slope and the safety factor values calculated using the limit equilibrium method. Based on the analytical solutions, this approach combines simple infiltration models to calculate the change in pore water pressure caused by rain infiltration within the slope using a sliding-block model to assess whether a slope failure occurred owing to a prescribed rainfall or not (Conte and Troncone 2012b).

The slope stability analysis considers the condition of reservoir water level variations through various regorous slice methods in the existing traditional limit equilibrium methods (Bishop 1955; Morgenstern and Price 1965; Spencer 1967; Fellenius 1936; Janbu 1937). These traditional slice methods are considered under local analysis methods. 
Accordingly, another type can be called as integral analysis method, which includes diagrammatic method (Sarma 1972), variation method (Baker 2005) and integral analysis method by Bell (1968). Different from other limit equilibrium methods, the Bell model (Bell 1968) uses the whole sliding mass instead of a single slice as the object of study, in which the inter-slice force is not required, and hence opened up new avenues for the realization of the regorous method. Similar approaches are used and tested by number of researchers (Zhu et al. 2002 2005; Zheng and Tham 2009; Sun et al. 2016c), which indicates their popularity until 2002. Similar to Bell's derivation process, Zhu et al. ( Zhu et al. 2002 2005) deduced the cubic equation by taking the safety factor unknown and using an approximation of the normal stress distribution at slip surface through quadratic interpolation. Zheng and Tham (2009) transformed the domain integral into boundary integral by using Green's theorem, without slicing the sliding mass, to achieve the integral limit equilibrium analysis of the sliding mass.

For the first problem, this paper applied the Boussinesq's basic differential equation and boundary conditions of unsteady seepage flow to derive the calculation formula of the phreatic line during the decline of the reservoir water level. The polynomial fitting method is used to get the simplified formula for engineering applications. For the second problem, based on the assumption that the water level is parallel to the slope with infinite length (Conte and Troncone 2011), the relationship between rainfall and phreatic line is derived and established. Comprehensively by using the reservoir water level fluctuations and rainfall on phreatic line of the slope, an integral method for the analysis of slope stability under hydrodynamic forces is proposed. Finally, by applying all the methods on a typical ancient landslide in Three Gorges Reservoir area, the evolution of the slope stability under rainfall and reservoir water level fluctuations is studied.

\section{Calculation of groundwater phreatic line of slope}

Following the basic assumptions as given in section "Basic assumptions", the slope phreatic lines under reservoir water level fluctuations and rainfall are derived, 
and the corresponding simplified methods are proposed.

\section{Basic assumptions}

(1) The aquifer is homogeneous and isotropic with infinite lateral extension;

(2) The phreatic flow parallel with slope surface is caused by water-level fluctuation and the rainfall infiltration causes that phreatic flow perpendicular to slope surface;

(3) The reservoir water level is decreasing at a constant speed of $V_{0}$;

(4) The reservoir bank is considered as a vertical slope. The reservoir bank within the declining amplitude is much smaller than the ground, and in order to simplify this, it is considered as vertical reservoir bank.

As shown in Fig. 1, the differential equation of motion of the unsteady phreatic water under the above assumptions can be obtained by the Boussinesq equation as follows:

$$
\frac{\partial h^{\prime}}{\partial t}=\frac{K}{\mu} \frac{\partial}{\partial x^{\prime}}\left(H \frac{\partial h^{\prime}}{\partial x^{\prime}}\right)
$$

Where $x^{\prime}$ and $h^{\prime}$ are the two coordinate axes of the local coordinate established on phreatic line (Fig.1). $H$ is the aquifer thickness, $t$ is time (d), $K$ is permeability coefficient, and $\mu$ is specific yield.

This is a second-order nonlinear partial differential equation, and some analytical solutions can be referenced to Jiang and Tang (2015) and Tang et al. (2016). Usually some simplified methods are employed to realize its linearization. Because of the tiny difference between the phreatic flow thicknesses at the beginning and end of the time interval in the calculation process of practical considerations, the simplified method is to approximate the aquifer thickness $H$ as a constant, presented by the average value of $h_{m}$ of phreatic flow thickness at the beginning and end of the time interval, thus the equation of motion of the simplified one-dimensional unsteady seepage flow can be obtained as follows:

$$
\frac{\partial h^{\prime}}{\partial t}=a \frac{\partial^{2} h^{\prime}}{\partial x^{\prime 2}}
$$


Where, $a=\frac{K h_{m}}{\mu}$ is a constant, $h_{m}$ is the average thickness of aquifer (m).

\section{Change of slope phreatic line caused by reservoir water level fluctuation}

The calculation is shown in Fig. 1. At the initial moment $(t=0)$, the water level of each point in the area is $h_{0,0}^{\prime}$. The change of the underground water level at the distance of $x^{\prime}$ from the reservoir bank at the time $t$, can be expressed as follows:

$$
u^{\prime}(x, t) \equiv h_{0,0}^{\prime}-h_{x^{\prime}, t}^{\prime}=\Delta h_{x^{\prime}, t}^{\prime}
$$

The water level in the section when $t=0$ is changed as $u^{\prime}(x, 0)=h_{0,0}^{\prime}-h_{x, 0}^{\prime}=0$. $u^{\prime}\left(x^{\prime}, t\right)$ is the expression of the reservoir water level variation at the distance of $x^{\prime}$ and the time $t$ in the local coordinate system. $h_{0,0}^{\prime}$ is the expression of the initial water level in the slope in local coordinate. $h_{x^{\prime}, t}^{\prime}$ is the expression of water level line at the time $t$ in local coordinate.

The reservoir water level is decreasing at a speed of $V_{0}$. After the occurrence of lateral seepage, at the section of $x^{\prime}=0, u^{\prime}(0, t)=h_{0,0}^{\prime}-h_{0, t}^{\prime}=V_{0} t \cos \alpha$; at the section of $x^{\prime} \rightarrow \infty, u^{\prime}(\infty, t)=0$.

By formula (3), the above unsteady seepage of groundwater in the semi-infinite aquifer with declining water level can be formulated as the following mathematical model:

$$
\left\{\begin{array}{l}
\frac{\partial u^{\prime}}{\partial t}=a \frac{\partial^{2} u^{\prime}}{\partial x^{\prime 2}}, \quad 0<x^{\prime}<\infty, t>0 \\
u^{\prime}\left(x^{\prime}, 0\right)=0, \quad 0<x^{\prime}<\infty \\
u^{\prime}(0, t)=V_{0} t \cos \alpha, \quad t>0 \\
u^{\prime}(\infty, t)=0, \quad t>0
\end{array}\right.
$$

The mathematical model described by formula (4) can be used to obtain the solutions of the differential equations by using Laplace transform and its inverse Laplace transform (Xue 1986; Li and Wang 1987):

$$
u^{\prime}\left(x^{\prime}, t\right)=V_{0} t \cos \alpha\left[\left(1+2 \lambda^{2}\right) \operatorname{Erfc}(\lambda)-\frac{2}{\sqrt{\vartheta}} \lambda e^{-\lambda^{2}}\right]
$$


Where, $\lambda=\frac{x^{\prime}}{2 \sqrt{a t}}=\frac{x^{\prime}}{2} \sqrt{\frac{\mu}{K h_{m} t}} . \quad \operatorname{Erfc}(\lambda)=\frac{2}{\sqrt{\pi}} \int_{\lambda}^{\infty} e^{-x^{\prime 2}} d x^{\prime}$ is function of residual error.

Let

$$
M(\lambda) \equiv\left(1+2 \lambda^{2}\right) \operatorname{Erfc}(\lambda)-\frac{2}{\sqrt{\vartheta}} \lambda e^{-\lambda^{2}}
$$

According to Fig. 1,

$$
u(x, t)=\frac{u^{\prime}\left(x^{\prime}, t\right)}{\cos \alpha}
$$

Thus, $h_{x, t}$ becomes:

$$
h_{x, t}=h_{0,0}-V_{0} t M(\lambda)
$$

Here, $h_{0,0}$ is the water level before reservoir water decline (m).

The above is the equation for the slope phreatic line in the constant declining reservoir water level condition. $M(\lambda)$ can be calculated according to Eq. (6), and the change curve is shown in Fig. 2. From Eq. (6), it can be seen that it is complex to calculate directly without using the integral, and therefore not convenient for project application. In order to obtain the expression convenient for engineering applications, the curve in Fig. 2 is fitted, and the fitting formula can be expressed as follows (Zheng et al. 2004):

$$
M(\lambda)=\left\{\begin{array}{cc}
0.109 \lambda^{4}-0.750 \lambda^{3}+1.928 \lambda^{2}-2.2319 \lambda+1 & (0 \leq \lambda<2) \\
0 & (\lambda \geq 0)
\end{array}\right.
$$

The simplified calculation formula of phreatic line can be obtained in the declining water level condition at constant velocity, which is consistent with the results of finite element calculation under the same condition, and therefore verifying its correctness. The expression can be represented as follows:

$$
h_{x, t}=\left\{\begin{array}{cc}
h_{0,0}-V_{0} t\left(0.109 \lambda^{4}-0.750 \lambda^{3}+1.928 \lambda^{2}-2.2319 \lambda+1\right) & (0 \leq \lambda<2) \\
h_{0,0} & (\lambda \geq 0)
\end{array}\right.
$$

Where, $\lambda=\frac{x \cos \alpha}{2} \sqrt{\frac{\mu}{K h_{m} t}}$. 


\section{Relationship between rainfall and groundwater level change in the slopes}

The relationship between rainfall and groundwater level to derive and establish a simple expression is defined in this section. As shown in Fig. 3, the angle between infinite slope and horizontal line is $\theta$ and $h(x, t)$ that defines the change in groundwater level in the vertical direction is due to rainfall infiltration.

Because of complex geologic and tectonic actions, large numbers of fractures of variable scales develop in the slopes, forming the principle pathways for groundwater flow (Jiang et al. 2013 2014). Some cracks or fissures can appear in the slope surface (Van Asch et al. 1996), through that rainfall seeps into the slope and this establish the observed relationship between rainfall and the groundwater level (Conte and Troncone 2016). This situation can also occurs in the low permeability soil having complex relationship between the rainfall and the groundwater level. Under the assumption that the rainfall and groundwater level changes synchronously and the water stored in the soil is gradually accumulated and it causes seepage of the water from the slope while the soil is saturated (Conte and Troncone 2016), the expression after $N$ times of rainfall events can be get as:

$$
h(x, t)=\sum_{j=1}^{N} \frac{h_{r j}}{n\left(1-S_{r}\right)} \exp \left[-k_{T} i \cos \theta\left(t-t_{0 j}\right)\right]
$$

Where, $h_{r j}$ is the volume of water in the slope (unit area) due to the rainfall infiltration in $j$ th time, $k_{T}=k / b$, with unit width $b$ of a differential slope slice. Further, the expressions as Eq. (11) is derived by Montrasio and Valentino (2007) for calculating the triggering mechanism of rainfall-induced shallow landslides and by Conte and Troncone (2016) for the study of infinite slope.

\section{Determination of aquifer thickness}

In the previous analysis, in order to solve Eq. (1) during linearization, $H$ in the formula is replaced by the average value $h_{m}$ of phreatic flow thickness at the beginning and the end of the time interval, while $h_{m}$ is considered as aquifer thickness of the phreatic flow. The assumption is adequate in the condition when the declining level is relatively small, but when it is large, greater will be the error and thus require 
the following method to determine the thickness of the aquifer. The average thickness of the aquifer is not as simple as that of the irregular impermeable layer as shown in Fig. 5, which is common in projects. Therefore, it is necessary to put forward a method for engineering applications to determine the aquifer thickness.

For the geological conditions of the Three Gorges Reservoir area, the stratum surface is mostly consist of weathered soil and collapsed accumulation bodies, while the interior is the rock mass. In this way, the geological structure is formed with the upper part comprises of gravel soil and the lower part with rock mass. Compared with the soil, the permeability coefficient of rock mass is very small and can be neglected. The interface of rock mass and soil can be considered as impermeable layer. As shown in Fig. 5, when the reservoir water level declines, its calculation area is limited by rock stratum (impermeable layer), therefore the influence area cannot be determined using the horizontal impermeable layer. For this case, the following method is used to determine the average thickness of aquifer.

For practical landslides, in case other than a vertical slope and in the declining water level in the reservoir, the overflow point often appears on the slope surface, and then flows along the slope, which indicates that the phreatic line of slope is relatively gentle. Based on this situation, the initial water level and the slope surface can be used to replace the phreatic line in the calculation of the average aquifer thickness as shown in Fig. 5. The following formula can be used to calculate the average aquifer thickness,

$$
h_{m}=\frac{S_{o a b c}}{R}
$$

Where, $S_{o a b c}$ is the area of the curve formed by slope surface $o a$, initial water level line $a b$, bedrock surface $b c$, and $o c$ at the intersection point between the declining reservoir water level and the slope; $R$ is the intersection of initial water level and bedrock surface. Normally, the geological section can be drawn using Computer Aided Design (CAD), and therefore the area of the curved shape can be very easily determined. This method is found very practical for engineering applications and practices (Zheng et al. 2004). If $o a b c$ ( $c$ and $R$ are coincident) is foursquare in Fig. 5, 
$h_{m}=L_{o a}\left(L_{o a}\right.$ is the length of $\left.o a\right)$. In cases that $o a b c$ is triangle ( $c$ and $R$ are coincident; $a$ and $o$ are coincident) and $o a b$ is parabola, $h_{m}$ will be $b R / 2$ and $2 b R / 3$ respectively .

\section{Determination of specific yield}

Specific yield is a very important hydrogeological parameter, and its value should be determined using the practical test method. Specific yield is the amount of water that can be released by gravity from the saturated soil of unit volume or can be defined as the ratio of the volume of water released by gravity to the volume of the soil, in saturated soil conditions.

In the soil, water generally pass through the connected pores, as all the pores are not filled with the water, these pores are generally referred as effective pores in hydrogeology and accounts for only part of the total pores. It is also called "effective porosity" in hydrogeology, while in groundwater dynamics it is the ratio of pore volume that are filled with water and obtained after the water releases by the gravity to the volume of the rock and soil that contains the pore. Its value is directly controlled by the physical properties of the rock and the soil, and is comparable to the effective porosity of the rock and soil, but the latter is often expressed as a percentage.

According to the test data of gravel and cohesive soil in China and abroad (Mao et al. 1999), the empirical formula for specific yield is obtained as follows:

$$
\mu=1.137 n(0.0001175)^{0.067(6+\lg K)}
$$

Where, $n$ is porosity; $K$ is permeability coefficient with unit of $\mathrm{cm} / \mathrm{s}$. If no test data are available, Eq. (13) can be used to determine the specific yield.

\section{Normal stress on slip surface under hydrodynamic and surface water}

\section{pressure}

\section{Calculation of seepage force (hydrodynamic forces)}

Seepage force is the drag force created by the water on the soil particles under the action of seepage, also called as hydrodynamic forces by engineers. The calculation of seepage force is the key factor to evaluate slope stability under seepage, so its correct measurements determine the accuracy of the evaluation results. At present, many technical personnels have some confusion in the concept that is why 
they often use the surrounding hydrostatic force, and at the same time the seepage force as a separate load into the account, which resulted in repeated calculation of seepage force. In the calculation of seepage force, some consider the effect of void ratio, while some do not. Some engineers are often very confused about how to calculate the seepage force. In order to clarify the misconception, analysis can be started by using the water pressure acting on the differential slice boundary and the simplest force analysis to understand the calculation method of seepage force (Zheng et al. 2004).

A differential slice is taken out of the slope, and the force schematic diagram is shown in Fig. 6. In the figure, $d W_{1}$ is the soil gravity above the phreatic line, $d W_{2}$ is the gravity of saturated soil below the phreatic line, $P_{a}$ is the resultant force of hydrostatic forces of boundary $A B, P_{b}$ is that of boundary $C D, U$ is that of boundary $B C, N$ is the normal force between soil particles namely effective force, $\alpha$ is the angle between the differential slice bottom surface and horizontal direction, and $\beta$ is the angle between the phreatic line and the horizontal direction.

The hydrostatic forces $P_{a}, P_{b}$ and $U$ of the boundaries $A B, C D$ and $B C$ respectively can be determined according to the properties of flow and the streamline is perpendicular to the equipotential line. As shown in Fig. 7, draw $B E$ and $C G$ perpendicular to the phreatic line (streamline), then make $G H$ perpendicular to $C D$, and $E F$ perpendicular to $A B$, so that the water head $B F$ of point $B$ and water head $C H$ of point $C$ can be obtained. From the geometric relationship,

$$
U_{B}=h_{a} \cos ^{2} \beta, \quad U_{C}=h_{b} \cos ^{2} \beta
$$

The resultant force of hydrostatic forces acting on the boundary $A B$ and $C D$ can be expressed as:

$$
P_{a}=\frac{1}{2} \gamma_{w} h_{a}^{2} \cos ^{2} \beta, \quad P_{b}=\frac{1}{2} \gamma_{w} h_{b}^{2} \cos ^{2} \beta
$$

The resultant force of hydrostatic pressure acting on the slip surface $B C$ can be represented as:

$$
U=\frac{\gamma_{w}\left(h_{a}+h_{b}\right) d s}{2} \cos ^{2} \beta
$$


The components of the force in the vertical and horizontal direction can be represented as:

$$
\left\{\begin{array}{l}
U_{y}=\frac{\gamma_{w}\left(h_{a}+h_{b}\right) d s}{2} \cos \alpha \cos ^{2} \beta \\
U_{x}=\frac{\gamma_{w}\left(h_{a}+h_{b}\right) d s}{2} \sin \alpha \cos ^{2} \beta
\end{array}\right.
$$

While, the weight of water in the differential slice is

$$
W_{2 w} \equiv \frac{\gamma_{w}\left(h_{a}+h_{b}\right) d s}{2} \cos \alpha
$$

Where, $W_{2 w}$ is the gravity of water below the phreatic line in the differential slice.

By taking,

$$
h_{w} \equiv \frac{h_{a}+h_{b}}{2}
$$

The equation can be expressed as:

$$
\begin{gathered}
P_{a}-P_{b}=\gamma_{w} h_{w}\left(h_{a}-h_{b}\right) \cos ^{2} \beta \\
w_{2 w}=h_{w} \gamma_{w} d s \cos \alpha \\
\left\{\begin{array}{l}
U_{y}=\gamma_{w} h_{w} d s \cos \alpha \cos ^{2} \beta \\
U_{x}=\gamma_{w} h_{w} d s \sin \alpha \cos ^{2} \beta
\end{array}\right.
\end{gathered}
$$

The analysis of forces of all the water loads below the phreatic line in the differential slice is conducted as shown in Fig. 8.

The component of all water loads in $\mathrm{x}$ direction is as follows:

$$
P_{a}-P_{b}+U_{x}=\gamma_{w} h_{w} \cos ^{2} \beta\left(h_{a}-h_{b}+d s \sin \alpha\right)
$$

The component of all water loads in $y$ direction can be expressed as:

$$
d W_{2 w}-U_{y}=\gamma_{w} h_{w} d s \sin ^{2} \beta
$$

From the geometric relations in Fig. 8, it becomes:

$$
h_{a}-h_{b}+d s \sin \alpha=d s \cos \alpha \tan \beta
$$

Therefore, the resultant force of all water loads can be expressed as:

$$
d W_{D}=\gamma_{w} h_{w} d s \cos \alpha \sin \beta
$$

The geometric meaning is the product of saturation area, water unit weight, hydraulic 
gradient $\sin \beta$ of the differential slice. The value is equal to seepage or hydrodynamic forces, and its direction is same as the direction of flow with angle $\beta$ between the horizontal directions.

It is proved that, below the phreatic line, seepage force is the same force as the resultant force of water gravity and the surrounding hydrostatic force of the differential slice. Therefore, when using seepage force to express safety factor, natural unit weight is taken into account for the soil above the phreatic line, while the effective unit weight and seepage forces for below the phreatic line. Thus the calculation in Fig. 6 can be replaced by Fig. 9, so the water load surrounding the differential slice and water gravity can be exchanged by the seepage force $d W_{D}$, which makes the problem clear and simple.

\section{Expression of normal stress on slip surface under water load}

A differential slice $A B C D$ with arc length $d s$ is selected along the sliding resistance direction on slip surface $s$, and the schematic diagram is shown in Fig. 9. $d h$ and $d v$ are horizontal and vertical increment of inter-slice force, respectively; $d w$ and $d q$ are the slice weight and earthquake force, respectively; $d f_{x}$ and $d f_{y}$ are the horizontal and vertical component of forces acting on the slope outer contour $g$.

The relationship between the normal surface force $\bar{q}_{n}$ and the tangential surface force $\bar{q}_{t}$ on $g$ can be expressed as follows:

$$
d f_{x}=\bar{q}_{t} d x_{g}-\bar{q}_{n} d y_{g}, \quad d f_{y}=\bar{q}_{n} d x_{g}+\bar{q}_{t} d y_{g}
$$

Where, $d x_{g}$ and $d y_{g}$ are the components of the differential arc lengths respectively, $d s_{g}$ can be considered in the direction of $x$ and $y$ along the positive direction of $g$, as shown in Fig. 9.

By projecting all the forces of the slice in the normal direction of the slip surface, the equation can be obtained as: 
$\sigma d s=d W_{1} \cos \alpha+d W_{1}^{\prime} \cos \alpha+d W_{D y} \cos \alpha-d W_{D x} \sin \alpha+d f_{x} \sin \alpha-d f_{y} \cos \alpha+d v \cos \alpha-d h \sin \alpha$

Since

$$
\begin{aligned}
& \left\{\begin{array}{l}
d W_{1}=\bar{\gamma} h_{u} d x \\
d W_{1}^{\prime}=\bar{\gamma}^{\prime} h_{w} d x
\end{array}\right. \\
& \left\{\begin{array}{l}
d W_{D x}=d W_{D} \cos \beta \\
d W_{D y}=d W_{D} \sin \beta
\end{array}\right.
\end{aligned}
$$

Where, $h_{u}$ is the height of the differential slice above the phreatic surface, $\bar{\gamma}$ is the average unit weight of the slice, and $\vec{\gamma}^{\prime}$ is the average effective unit weight of the slice.

By substituting the Equations (27), (29) and (30) into (28), and with $d x_{g}=-d x$ it can be rewritten as:

$$
\sigma=\sigma(x)=\sigma_{0}+\sigma^{I}
$$

Where, $\sigma^{I}$ and $\sigma_{0}$ are the contributions of normal stress at slip surface from inter-slice force and external load respectively, and they are all can be represented in terms of $x$.

$$
\sigma^{I}=\cos \alpha\left(\frac{d v}{d x} \cos \alpha-\frac{d h}{d x} \sin \alpha\right)
$$

$\sigma_{0}$ can be decomposed into,

$$
\sigma_{0}=\sigma_{0}^{v}+\sigma_{0}^{g}
$$

Where, $\sigma_{0}^{v}$ is the contribution of normal stress at slip surface from the volume force of the sliding body.

$$
\sigma_{0}^{v}=\bar{\gamma} h_{u} \cos ^{2} \alpha+\bar{\gamma}^{\prime} h_{w} \cos ^{2} \alpha+\gamma_{w} h_{w} \cos ^{2} \alpha \sin ^{2} \beta-\frac{\gamma_{w} h_{w} \sin 2 \alpha \sin 2 \beta}{4}
$$

$\sigma_{0}^{g}$ is contribution on normal stress at slip surface from water pressure on slope outer contour $g$.

$$
\sigma_{0}^{g}=\cos \alpha\left[\bar{q}_{n}\left(\cos \alpha+k_{g} \sin \alpha\right)-\bar{q}_{t}\left(\sin \alpha-k_{g} \cos \alpha\right)\right]
$$


Where, $k_{g}$ is the slope of the outer contour $g$.

Although under normal circumstances, the inter-slice force $v$ and $h$ are 0 at both ends of the slip surface, but their derivatives $\frac{d v}{d x}$ and $\frac{d h}{d x}$ are not necessarily 0 ; By Eq. (31) and Eq.(32), it can be seen that normal stresses at both ends of the slip surface are not 0 . Therefore, when constructing normal stress distribution of the slip surface, there is no need to meet the condition of 0 at both ends of the slip surface. The normal stress distribution of the slip surface can be configured as follows for its approximation and can be represented by Eq. (31).

$$
\sigma=\sigma_{0}+f(x ; a, b)
$$

Where, $f(x ; a, b)$ is the correction function of normal stress on slip surface; $a$ and $b$ are two parameters to be determined. The reason of the introduction of two undetermined parameters is that there are only 3 equilibrium equations (Eq. (39)) to solve the 3 unknowns, and the safety factor $F_{s}$ has already occupied one of them. So, the $f(x ; a, b)$ can be expressed as a linear function (Zheng and Tham 2009) as follows:

$$
\begin{gathered}
f(x ; a, b)=a l_{a}(x)+b l_{b}(x) \\
l_{a}(x)=-\frac{x-\bar{x}_{b}}{\bar{x}_{b}-\bar{x}_{a}}, \quad l_{b}(x)=\frac{x-\bar{x}_{a}}{\bar{x}_{b}-\bar{x}_{a}}
\end{gathered}
$$

Where, $\bar{x}_{a}$ and $\bar{x}_{b}$ are the $x$ coordinates of two end points of the slip surface $s$ respectively.

\section{Analysis method of slope stability under water load}

As shown in Fig. 10, plane area $\Omega$ is surrounded by the slope contour $A C B$ and the potential slip surface $A D B$, which is defined here as a landslide mass, composed of varieties of geomaterials. The active forces on landslide mass include volume force (gravity and horizontal earthquake force etc.), surface force and concentrated force acting on the outer contour $A C B$. The constraint forces include the normal force $\sigma(x) d s$ and tangential force $\tau(x) d s$ on the slip surface. 
By taking any three points $\left(x_{c i}, y_{c i}\right), i=1,2,3$ not in a straight line as the centers of the moment and by taking $\Omega$ is in a state of equilibrium, the resultant moment to the three points can be obtained as 0 for the force system acting on that, can be expressed as:

$$
\int_{S}\left(\Delta x_{c i} \sigma-\Delta y_{c i} \tau\right) d x+\left(\Delta x_{c i} \tau+\Delta y_{c i} \sigma\right) d y+m_{c i}=0
$$

Where, $m_{c i}$ is the moment of all the active forces on the landslide mass $\Omega ; \Delta x_{c i}$ and $\Delta y_{c i}$ are the components of position vectors from $\left(x_{c i}, y_{c i}\right)$ to $(x, y)$ of the slip surface respectively:

$$
\Delta x_{c i}=x-x_{c i}, \quad \Delta y_{c i}=y-y_{c i}
$$

The subscript $i$ in this section is a free subscript. When it appears in a formula, it is taken as 1, 2 and 3 respectively, indicating the three moment centers $\left(x_{c i}, y_{c i}\right)$ to obtained the three formulas. At the same time, in order to describe it simply, it is assumed that the slope is right-slope, which means the slope height increases with the increase in $x$ coordinate.

By assuming that the slip surface satisfy the Mohr-Coulomb criterion, i.e. the landslide mass is in the limit equilibrium state, the equation can be written as:

$$
\tau=\frac{1}{F_{s}}\left[c_{e}+f_{e} \sigma\right]
$$

Where, $F_{s}$ is safety factor; $c_{e}$ and $f_{e}$ are the shear strength parameters of effective stresses.

By substituting the Eq. (40) into Eq. (39), integral equations of slip surface with normal stress as an unknown function can be obtained as:

$$
\int_{S} L_{c i}^{x} \sigma d x+L_{c i}^{y} \sigma d y+m_{c i} F_{s}+d_{c i}=0
$$

Where,

$$
\begin{gathered}
L_{c i}^{x}=F_{s} \Delta x_{c i}-f_{e} \Delta y_{c i}, \quad L_{c i}^{y}=F_{s} \Delta y_{c i}+f_{e} \Delta x_{c i} \\
d_{c i}=\int_{S} c_{e} \Delta x_{c i} d y-c_{e} \Delta y_{c i} d x
\end{gathered}
$$

By substituting the Eq. (36) into Eq. (41), it becomes:

$$
\boldsymbol{g}\left(F_{s}, a, b\right) \equiv F_{s}\left(a \boldsymbol{u}_{1}+b \boldsymbol{u}_{2}+\boldsymbol{u}_{3}\right)+a \boldsymbol{u}_{4}+b \boldsymbol{u}_{5}+\boldsymbol{u}_{6}
$$


Where, $g: R^{3} \rightarrow R^{3}$ is the function of $F_{s}, a$ and $b$ according to the above definition; $\boldsymbol{u}_{1} \sim \boldsymbol{u}_{6}$ are the six 3 -order vectors, defined by the following equations:

$$
\begin{gathered}
u_{1, j}=\int_{S} \Delta x_{c i} l_{a} d x+\Delta y_{c i} l_{a} d y \\
u_{2, j}=\int_{S} \Delta x_{c i} l_{b} d x+\Delta y_{c i} l_{b} d y \\
u_{3, j}=m_{c i}+\int_{S} \Delta x_{c i} \sigma_{0} d x+\Delta y_{c i} \sigma_{0} d y \\
u_{4, j}=-\int_{S} f_{e} \Delta y_{c i} l_{a} d x-f_{e} \Delta x_{c i} l_{a} d y \\
u_{5, j}=-\int_{S} f_{e} \Delta y_{c i} l_{b} d x-f_{e} \Delta x_{c i} l_{b} d y \\
u_{6, j}=-\int_{S}\left(c_{e}+f_{e} \sigma_{0}\right) \Delta y_{c i} d x-\left(c_{e}+f_{e} \sigma_{0}\right) \Delta x_{c i} d y
\end{gathered}
$$

The functions of Eq. (42) can be solved by the quasi-Newton method (Heat 2002). Here, Jacobian of $\boldsymbol{g}\left(F_{s}, a, b\right)$ is required in the solution procedure, can be defined as $D \boldsymbol{g}$ :

$$
D \boldsymbol{g}\left(F_{s}, a, b\right) \equiv\left[D \boldsymbol{g}_{F_{s}}, D \boldsymbol{g}_{a}, D \boldsymbol{g}_{b}\right]
$$

Where, the three column vectors can be expressed as follows:

$$
\begin{aligned}
& D \boldsymbol{g}_{F_{s}} \equiv \frac{\partial \boldsymbol{g}\left(F_{s}, a, b\right)}{\partial F_{s}}=a \boldsymbol{u}_{1}+b \boldsymbol{u}_{2}+\boldsymbol{u}_{3} \\
& D \boldsymbol{g}_{a} \equiv \frac{\partial \boldsymbol{g}\left(F_{s}, a, b\right)}{\partial a}=F_{s} \boldsymbol{u}_{1}+\boldsymbol{u}_{4} \\
& D \boldsymbol{g}_{b} \equiv \frac{\partial \boldsymbol{g}\left(F_{s}, a, b\right)}{\partial b}=F_{s} \boldsymbol{u}_{2}+\boldsymbol{u}_{5}
\end{aligned}
$$

In this study, the iterative process for solving the equations is stopped by using the following condition as mentioned in Eq. (44). After meeting the following condition, the iterations will be stopped and the solutions of the unknowns are obtained. The condition can be expressed as follows:

$$
\Delta F_{s}<\varepsilon_{F_{s}}
$$

Where, $\Delta F_{s}$ is the difference between the two consecutive iteration steps; $\varepsilon_{F_{s}}$ is the artificially defined allowable value of the safety factor. 
In all the above cases, $\varepsilon_{F_{s}}=10^{-3}$ is applied using the damped Newton method (Heat 2002). The boundaries of landslide mass are discretized into grids of micro-line segments, on which the normal stress of the slip surface is assumed to be constant.

In this section, a simply slope with measured data of the groundwater level in the Three Gorges Reservoir reduring the water level drawdown from November 2008 to June 2009 will be employed to verify the simplified method for phreatic line calculation of slopes and the global analysis method to solve the slope safety factor. Physical and mechanical parameters are shown in Table 1. The Geometry, changing process of the underground water and the monitoring poits $\mathrm{J} 1$ and $\mathrm{J} 2$ are shown in Fig. 11.

The monitored underground water level at $\mathrm{J} 1$ was unchanged, which is similar to the results from the the simplified method. The monitored elevation data of underground water level at $\mathrm{J} 2$ was $179.30 \mathrm{~m}$ in November 2008. After water level drawdown the monitored elevation data at J2 was $173.82 \mathrm{~m}$ in June 2009 and the results from the proposed method is $174.15 \mathrm{~m}$. The error between the two results is acceptable in engineering practice. The safety factor of the proposed method under the condition of the underground water level in November 2008 is 1.06, and that from the Morgenstern-Price method is 1.05 . However, the afety factor of the proposed method under the condition of the underground water level in June 2009 is 1.05, and that from the Morgenstern-Price method is 1.03. In addition, the factors of safety and the changes of the underground water level from Eq. (10) and Eq. (5) are same because of the tiny error between the two curves of Eq. (10) and Eq. (5).

\section{The evolution of slope stability under the combined effect of reservoir}

\section{water level fluctuation and rainfall}

This section applies a practical slope in the Three Gorges Reservoir area to study the evolution of stability under the combined effects of reservoir water level fluctuation and rainfall.

Woshaxi slope is located on the right bank of Qinggan River, which is a tributary of the Yangtze River. Qinggan River runs from west to east and passes through the 
leading edge of the landslide, which is about $6 \mathrm{~km}$ from the estuary and about $1.5 \mathrm{~km}$ from Qianjiangping landslide on the left bank of the the river (Chen et al. 2003; Yin et al. 2012; Sun et al. 2016a 2016b; Xiao et al. 2010a 2010b; Yin et al. 2015; Wang et al. 2016). The geographical location is shown in Fig. 12.

Woshaxi landslide mass is high in the south and west, while low in the north and east side. The altitude of the trailing edge of the landslide mass is about $405 \mathrm{~m}$. The leading edge is found below $140 \mathrm{~m}$, while the left and right boundaries of the landslide are bounded by the bedrock ridge and valley, with the general slope of $20^{\circ}$. The length of the sliding mass is $400 \mathrm{~m}$, width is $700 \mathrm{~m}$, average thickness is about 15 $\mathrm{m}$, and the volume is about $4.2 \times 10^{6} \mathrm{~m}^{3}$. On February 24,2007 , at the central leading edge of the landslide, a secondary landslide appeared with obvious slip deformations. It is found that the trailing edge of the secondary landslide area is located on the village road with an altitude of about $225 \mathrm{~m}$, and the leading edge is found below at an altitude of $152 \mathrm{~m}$ to the reservoir water level of Qinggan River (water level on March 10, 2007). The width of the landslide is found about $110 \mathrm{~m}$ in east-west direction, lengthwise it is about $300 \mathrm{~m}$, plane area is about $3.3 \times 10^{4} \mathrm{~m}^{2}$, and total volume is about $50 \times 10^{4} \mathrm{~m}^{3}$. The geological section is shown in Fig. 13 .

Fig. 14 shows the change curve of reservoir water level during the first impoundment of the Three Gorges Reservoir and the average monthly rainfall during the period. In this section, the evolution of the stability of Woshaxi landslide is analyzed during the period under consideration. Physical and mechanical parameters are shown in Table 2, along with the different values applied with respect to the three parameters-permeability coefficient, porosity and saturation that affect the phreatic line of the slope. In this study, $k_{\mathrm{T}}$ will be obtained by $k_{T}=K / b$ with unit width $b=1$. In order to analyze the influence of the parameters indicated in Table 2 on the safety factor, the three conditions are taken into account: 1) reservoir water level variation only; 2) rainfall only and 3) combined effects of both the rainfall and reservoir water level fluctuation, as shown in Fig. 15-22.

Without considering the rainfall, the safety factor of Woshaxi landslide changes 
according to the reservoir water level. As shown in Fig.15, when the reservoir water level rises, it also increases the safety factor and vice versa. It could be ascribed to the increase in pressure on the foot of the slope because of rising water level as well as to the surface water pressure and the hydrodynamic forces pointing to the inner slope. These factors are also found responsible for increasing the stability of the slope. The reason for the latter is that when the reservoir water level declines, force at the foot of the slope reduces, which causes a reduction in the surface water pressure and hydrodynamic forces pointing to the outer slope. This leads to a formation of drag force, which is unfavorable for the stability of slope. As shown in Fig. 15, when the values of permeability coefficient $K$ are $0.01 \mathrm{~m} / \mathrm{d}, 0.1 \mathrm{~m} / \mathrm{d}$ and $1 \mathrm{~m} / \mathrm{d}$ respectively and having other parameters unchanged, the safety factor of Woshaxi landslide changes very little during the first impoundment. On the other hand, in case of the porosity $n$ with the values $0.1,0.3$ and 0.5 and other parameters unchanged, the obtained safety factors are almost the same, as shown in Fig. 16. The analysis indicates that without considering the rainfall, the safety factors of Woshaxi landslide is basicly higher, and the permeability coefficient and porosity have little effect on the global safety factor when they are calculated in the normal parameter ranges.

Figures 17-19 are showing the calculation results after considering the rainfall only. The results show that the safety factors are significantly lower than that of calculated with reservoir water level fluctuations only. Safety factor varies with the change of monthly rainfall. From the trend analysis, it shows that the rainfall and safety factors are having inverse relationships in Woshaxi area. This is because an increase in the rainfall causes an increase in the phreatic line of the slope, and as a result the hydrodynamic forces increases and the safety factor decreases. As shown in Fig. 17, the permeability coefficient $K$ is $0.01 \mathrm{~m} / \mathrm{d}, 0.1 \mathrm{~m} / \mathrm{d}$ and $1 \mathrm{~m} / \mathrm{d}$ respectively. With the other parameters remains unchanged, the variation trend of the safety factors of the Woshaxi landslide is consistent during the first impoundment period, however, it increases with the increase in the $K$. This is because a higher value of $K$ increases the soil permeability above the phreatic line, and hence more difficulty for the rainwater to be permeated in the soil and to form hydrodynamic forces, as given in Eq. 
(26). Moreover, it is found that a slow increase in the amplitude of phreatic line will leads to a smaller increase in the hydrodynamic forces and therefore high safety factor. On the contrary, with the different permeability coefficients, the safety factors in the same state do not varied much. As shown in Fig. 18, the values of porosity $n$ are 0.1 , 0.3 and 0.5 respectively, with the other parameters unchanged, the safety factors of Woshaxi landslide are consistent during the first impoundment period, however with the increase in $n$, the safety factor is also increased. This is because the higher the value of $n$, the better the soil permeability above the phreatic line will be, and therefore the more difficult for the rainwater to be permeated in the soil and to form hydrodynamic forces, such as given in Eq. (26). Further, it is found that a slow increase in amplitude of phreatic line will leads to higher safety factor. As shown in Fig. 19, saturation of the soil $S_{\mathrm{r}}$ above the phreatic line are $0.1,0.3$ and 0.5 respectively, with the other parameters remains the same, the safety factor of Woshaxi landslide is consistent during the first impoundment period, but with the increase in $S_{\mathrm{r}}$ values the safety factor decreases. This is because the higher the value of $S_{\mathrm{r}}$, the worse the soil permeability above the phreatic line will be, and hence easier for the rainwater to be permeated in the soil and to form hydrodynamic forces, such as given in Eq. (26). Further, a fast increase in the amplitude of the phreatic line will leads to a greater development of the hydrodynamic forces, and hence a lower safety facor. However, with different saturation, the safety factor in the same state is not found very different. Overall, the porosity of the soil above the phreatic line has a big influence on the safety factors under rainfall, while smaller affects are detected for permeability coefficient and saturation.

Fig. 20-22 shows the evolution of the stability of the Woshaxi landslide under the combined effect of reservoir water level fluctuation and the rainfall during the first impoundment period. From the previous analysis, the decline in reservoir water level and increase in rainfall causes a decrease in safety factors of the slope. On the contrary, the increase in the reservoir water level and decrease in rainfall leads to an increase in the safety factors of slope. In the condition with declining reservoir water level and increase in rainfall, the slope stability gets decreases for the cases having the 
combined effects of the reservoir water level fluctuations and the rainfall, as shown in Fig. 20-22. The safety factors are showing a decreasing trend during the months of April to May in the years 2007-2009. With the increasing reservoir water level and decreasing rainfall, the slope stability shows an improvement, as shown in Fig. 20 to 22. For the months November to September of the years 2007-2009, the safety factor is showing a rise in its values. Therefore, in order to prevent the occurrence of geological disaster like landslide in the Three Gorges Reservoir area, the rapid drawdown of the reservoir water level should be avoided in the rainy season. The three parameters (permeability coefficient, porosity and saturation) affect the phreatic line of slope and safety factor variably. For slope stability, engineers can refer to rainfall or reservoir water level fluctuations or both i.e. the combined effects of reservoir water level fluctuations and rainfall.

\section{Conclusions}

In order to improve the analytical method of slope stability under the combined effect of reservoir water level fluctuations and rainfall, this study established a simplified method for phreatic line calculation in internal slope under the combined effects of reservoir water level fluctuation and rainfall. Basic differential equations and boundary conditions given by Boussinesq for the unsteady seepage are used in this study to obtain the calculation formula of phreatic line in declining water level condition of reservoir. The polynomial fitting method is used to derive the simplified formula for engineers. Based on the continuity of the slope, a simple and practical relation is derived between the rainfall and phreatic line changes in the slope. Moreover, in this study, expressions of normal stress on slip surface of the slope are derived under hydrodynamic forces and an integral analysis method is proposed to solve slope safety factor under the hydrodynamic forces condition. Finally, by applying a practical engineering slope in the Three Gorges Reservoir area, the evolution of the slope stability is studied under the combined effects of reservoir water level fluctuation and rainfall during the first impoundment period. 


\section{Acknowledgments}

This study is supported by National Natural Science Foundation of China (Grant No: 11572009).

\section{References}

Alt, H.W. 1980. Numerical solution of steady-state porous flow free boundary problems. Numer Math., 31:73-98.

Baiocchi, C. 1972. Su un problema di frontiera libera connesso a questioni di idraulica. Ann Math Pura Appl., 91:107-27.

Baiocchi, C., and Capello, A. 1984. Variational and quasivariational inequalities. Applications to free boundary problems. New York: Wiley.

Baker, R. 2005. Variational slope stability analysis of materials with non-linear failure criterion. Electronic Journal of Geotechnical Engineering, 10: Bundle A: 1-22.

Bathe, K.J., and Khoshgoftaar, M.R. 1979. Finite element free surface seepage analysis without mesh iteration. Int J Numer Anal Meth Geomech., 3:13-22.

Bell, J.M. 1968. General slope stability analysis. Journal of the Soil Mechanics and Foundations Division, ASCE, 94(SM6):1253-1270.

Bishop, A.W. 1955. The use of the slip circle in the stability analysis of earth slopes. Geotechnique, 5(1): 7-17.

Brezis, H., Kinderlehrer, D., and Stampacchia, G. 1978. Sur une nouvelle formulation du probleme de l'ecoulement a travers une digue, Serie A. Paris: C. R. Academie des Sciences.

Calvello, M., Cascini, L., and Sorbino, G. 2008. A numerical procedure for predicting rainfall induced movements of active landslides along pre-existing slip surfaces. Int J Numer Anal Methods Geomech, 32(4):327-351. DOI: 10.1002/nag.624.

Chen, Y., Zhou, C., and Zheng, H. 2008. A numerical solution to seepage problems with complex drainage systems. Computers and Geotechnics, 35: 383-393. DOI: 10.1016/j.compgeo.2007.08.005.

Chen, Y.B., Wang, C.H., and Fan, X.Y. 2003. Landside feature and the genesis of Qianjiangping in 
Hubei province. Journal of mountain sciences, 21(5): 633-634.

Conte, E., and Troncone, A. 2012a. Stability analysis of infinite clayey slopes subjected to pore pressure changes. Geotechnique, 62(1):87-91. DOI: 10.1680/geot.10.T.002.

Conte, E., and Troncone, A. 2012b. Simplified Approach for the Analysis of Rainfall-Induced Shallow Landslides. J. Geotech. Geoenviron. Eng., 138(3): 398-406. DOI: 10.1061/(ASCE)GT.1943-5606.0000577.

Conte, E., and Troncone, A. 2016. A simplified method for predicting rainfall-induced mobility of active landslides. Landslides, online, DOI 10.1007/s10346-016-0692-8.

Cryer, C.W. 1970. On the approximate solution of free boundary problems using finite differences. J Assoc Comput Mach, 17(3):397-411.

Desai, C.S., and Li, G.C. 1983. A residual flow procedure and application for free surface flow in porous media. Adv Water Resour, 6:27-35.

Dong, Q., Xu, C., Cai, Y., and Juang, H. 2016. Drained Instability in Loose Granular Material. Int. J. Geomech., 16(2): 04015043. DOI: 10.1061/(ASCE)GM.1943-5622.0000524.

Duncan, J.M. 1996. State of the art: limit equilibrium and finite element analysis of slopes. Journal of Geotechnical and Geoenvironmental Engineering ASCE, 122(7): 577-596.

Fellenius, W. 1936. Calculation of the stability of earth dams, Transactions of the 2nd Congress on Large Dams, International Commission on Large Dams of the World Power Conference, 4: 445-462.

Finn, W.D.L. 1967. Finite-element analysis of seepage through dams. J Soil Mech Foundat Div ASCE, 93(SM6):41-8.

Friedman, A. 1982. Variational principles and free-boundary problems. New York: Wiley.

Heath, M.T. 2002. Scientific Computing: An Introductory Survey, 2nd ed. McGraw-Hill, New York.

Janbu, N. 1973. Slope stability computations, in: R.C. Hirschfield and S.J. Poulos (eds.), Embankment-Dam Engineering, pp. 47-86, John Wiley.

Ji, C.N., Wang, Y.Z., and Shi, Y. 2005. Application of medified EP method in steady seepage analysis. Computers and Geotechnics, 32:27-35. DOI: 10.1016/j.compgeo.2004.11.006.

Jiang, Q., and Tang, Y. 2015. A general approximate method for the groundwater response problem caused by water level variation. Journal of hydrology, 529: 398-409. DOI: 
10.1016/j.jhydrol.2015.07.030.

Jiang, Q., Yao, C., Ye, Z., and Zhou, C. 2013. Seepage flow with free surface in fracture networks. Water resources research, 49(1): 176-186. DOI: 10.1029/2012WR011991.

Jiang, Q., Ye, Z., and Zhou, C. 2014. A numerical procedure for transient free surface seepage through fracture networks. Journal of hydrology, 519: 881-891. DOI: 10.1016/j.jhydrol.2014.07.066.

Kikuchi, N. 1977. An analysis of the variational inequalities of seepage flow by finite-element methods. Quart Appl Math., 35:149-63.

Li, J., and Wang, Y. 1987. Groundwater dynamics. Beijing: Geology Publishing House, 155-156. (in Chinese).

Mao, C., Duan, X., and Li, Z. 1999. Seepage numerical computing and its applications. Nanjing: Hohai University Press, 10-11. (in Chinese).

Mohammad, A., Sivakugan, N., and Braja, M. 2015. Water Table Correction Factors for Settlements of Shallow Foundations in Granular Soils. Int. J. Geomech., 15(1): 06014015. DOI: 10.1061/(ASCE)GM.1943-5622.0000391.

Montrasio, L., and Valentino, R. 2007. Experimental analysis and modelling of shallow landslides. Landslides, 4(3):291-296. DOI: 10.1007/s10346-007-0082-3.

Morgenstern, N.R., and Price, V.E. 1965. The analysis of the stability of general slip surface. Geotechnique, 15:79-93.

Neuman, S.P., and Witherspoon, P.A. 1970. Finite element method of analyzing steady seepage with a free surface. Water Resour Res., 6(3):889-97.

Oden, J.T., and Kikuchi, N. 1980. Recent advances: theory of variational inequalities with applications to problems of flow through porous media. Int J Eng Sci., 18:1173-284.

Sarma, S.K. 1972. A note on the stability analysis of earth dams. Geotechnique, 22(3):164-166.

Spencer, E. 1967. A method of analysis of the stability of embankments assuming parallel inter-slice forces. Geotechnique, 17:11-26.

Sun, G., Cheng, S., Jiang, W., and Zheng, H. 2016c. A global procedure for stability analysis of slopes based on the Morgenstern-Price assumption and its applications. Computers and Geotechnics, 80: 97-106, DOI: 10.1016/j.compgeo.2016.06.014.

Sun, G., Zheng, H., Huang, Y., and Li, C. 2016a. Parameter inversion and deformation mechanism 
of Sanmendong landslide in the Three Gorges Reservoir region under the combined effect of reservoir water level fluctuation and rainfall. Engineering Geology, 205:133-145. DOI: 10.1016/j.enggeo.2015.10.014.

Sun, G., Zheng, H., Tang, H., and Dai, F. 2016b. Huangtupo landslide stability under water level fluctuations of the Three Gorges reservoir. Landslides, 13(5): 1167-1179, DOI 10.1007/s10346-015-0637-7.

Tang, Y., Jiang, Q., and Zhou, C. 2016. Approximate analytical solution to the Boussinesq equation with a sloping water-land boundary. Water resources research, 52(4): 2529-2550. DOI: 10.1002/2015WR017794.

Taylor, R.L., and Brown, C.B. 1967. Darcy flow solutions with a free surface. J Hydr Div, ASCE, 93:25-33.

Van Asch T. W. J., Hendriks, M. R., Hessel, R., and Rappange, F. E. 1996. Hydrological triggering conditions of landslides in varved clays in the French Alps. Eng Geol 42:239-251

Van Asch, T.W.J., and Buma, J.T. 1997. Modelling groundwater fluctuations and the frequency of movement of a landslide in the terres noires region of barcelonnette (France). Earth Surf Process Landf, 22:131-141.

Wang, F., Zhang, Y., Huo, Z., Matsumoto, T., and Huang B. 2004. The July 14, 2003 Qianjiangping landslide, Three Gorges Reservoir, China. Landslides, 1:157-162. DOI: 10.1007/s10346-004-0020-6.

Wang, F., Zhang, Y., Huo, Z., Peng, X., Wang, S., and Yamasaki, S. 2008. Mechanism for the rapid motion of the Qianjiangping landslide during reactivation by the first impoundment of the Three Gorges Dam reservoir, China. Landslides, 5:379-386. DOI: 10.1007/s10346-008-0130-7.

Wang, W., Yuan, W., Li, X., and Bai, B. 2016. Evaluation Approach of the Slope Stability Based on Deformation Analysis. Int. J. Geomech., 16(2): 04015054. DOI: 10.1061/(ASCE)GM.1943-5622.0000528.

Westbrook, D.R. 1985. Analysis of inequalities and residual flow procedures and an iterative scheme for free surface seepage. Int $\mathrm{J}$ Numer Meth Eng, 21:1791-802. DOI: 10.1002/nme.1620211006.

Xiao, S., Liu, D., and Hu, Z. 2010a. Study of high velocity slide mechanism of Qianjiangping 
landslide in Three Gorges Reservoir area. Rock Soil Mech., 31(11):3531-3536 (in Chinese).

Xiao, S., Liu, D., Jiang, F., and Jiang, X. 2010b. Geomechanical model experiment on Qianjiangping landslide in Three Gorges Reservoir area. Chin. J. Rock Mech. Eng., 29(5):1023-1030. (in Chinese).

Xue, Y. 1986. Theory on groundwater dynamics. Beijing: Geology Publishing House, 74-77. (in Chinese).

Yin, K., Liu, Y., Wang, Y., and Jiang, Z. 2012. Physical model experiments of landslide-induced surge in Three Gorges Reservoir. Earth Sci J China Univ Geosci, 37(5):1067-1074. DOI: 10.3799/dqkx.2012.113.

Yin, Y., Huang, B., and Chen, X. 2015. Numerical analysis on wave generated by the Qianjiangping landslide in Three Gorges Reservoir, China. Landslides, 12: 355-364. DOI: $10.1007 / \mathrm{s} 10346-015-0564-7$.

Zheng, H., Liu, D.F., Lee, C.F., and Tham, L.G. 2005. A new formulation of Signorini's type for seepage problems with free surfaces. Int J Numer Methods Eng, 64:1-16. DOI: 10.1002/nme. 1345 .

Zheng, H., and Tham, G. 2009. Improved Bell's method for the stability analysis of slopes. International Journal for Numerical and Analytical Methods in Geomechanics, 33:1673-1689. DOI: $10.1002 /$ nag. 794 .

Zheng, Y., Shi, W., and Kong, W. 2004. Calculation of seepage forces and phreatic surface under drawdown conditions. Chinese Journal of Rock Mechanics and Engineering, 23(18): 3203-3210. (in Chinese)

Zhu, D.Y., and Lee, C.F. 2002. Explicit limit equilibrium solution for slope stability. International Journal for Numerical and Analytical Methods in Geomechanics, 26: 1573-1590. DOI: 10.1002/nag.260.

Zhu, D.Y., Lee, C.F., and Chan, D.H. 2005. Evaluation of the stability of anchor-reinforced slopes. Canadian Geotechnical Journal, 42(5): 1342-1349. DOI: 10.1139/T05-060. 


\section{Figure captions:}

Figure 1. Calculation sketch of phreatic surface.

Figure 2. The curve of $M(\lambda)$.

Figure 3. Slope model with an indication of the steady-state groundwater level, the groundwater level change owing to rain infiltration, $h(x, t)$, and the slip surface (modified from Conte and Troncone 2016).

Figure 4. Rain depth, $h_{n}$, and potential rain infiltration depth, $\bar{h}$ (modified from Conte and Troncone 2016).

Figure 5 Calculation sketch of aquifer thickness.

Figure 6. Calculation sketch of differential soil slice.

Figure 7. Calculation sketch of hydraulic grade.

Figure 8. Forces distributing diagrammatic sketch of differential soil slice.

Figure 9. The schematic diagram of a loaded differential slice for derivation of normal stress on sliding surface.

Figure 10. Schematic plot of a sliding body and system of forces on it.

Figure 11. The geological section map and the changes of the underground water level of the verifiable example.

Figure 12. The geographical location map of Woshaxi Slope in the Three Gorges Reservoir.

Figure 13. The geological section map of Woshaxi Slope.

Figure 14. The average monthly rainfall and reservoir water level from 2007 to 2009.

Figure 15. Safety factors of the Woshaxi landslide under the condition of reservoir water level fluctuation from 2007 to 2009 (Different permeability coefficients).

Figure 16. Safety factors of the Woshaxi landslide under the condition of reservoir water level fluctuation from 2007 to 2009 (Different porosity).

Figure 17. Safety factors of the Woshaxi landslide under the condition of rainfall from 2007 to 2009 (Different permeability coefficients).

Figure 18. Safety factors of the Woshaxi landslide under the condition of rainfall from 2007 to 2009 (Different porosity). 
Figure 19. Safety factors of the Woshaxi landslide under the condition of rainfall from 2007 to 2009 (Different saturation).

Figure 20. Safety factors of the Woshaxi landslide under the coupling condition of reservoir water level fluctuation and rainfall from 2007 to 2009 (Different permeability coefficients).

Figure 21. Safety factors of the Woshaxi landslide under the coupling condition of reservoir water level fluctuation and rainfall from 2007 to 2009 (Different porosity).

Figure 22. Safety factors of the Woshaxi landslide under the coupling condition of reservoir water level fluctuation and rainfall from 2007 to 2009 (Different saturation).

\section{Table captions:}

Table 1 Parameters of verifiable example.

Table 2 Parameters of Woshaxi Slope. 


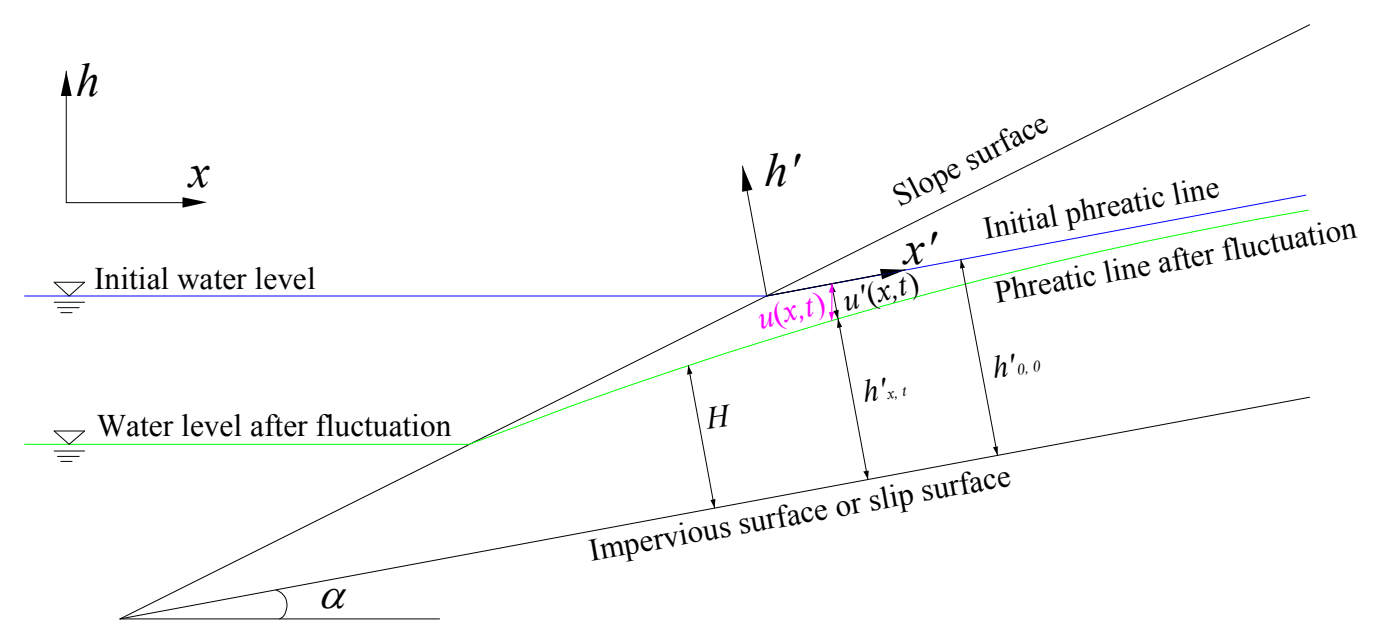

Figure 1. Calculation sketch of phreatic surface

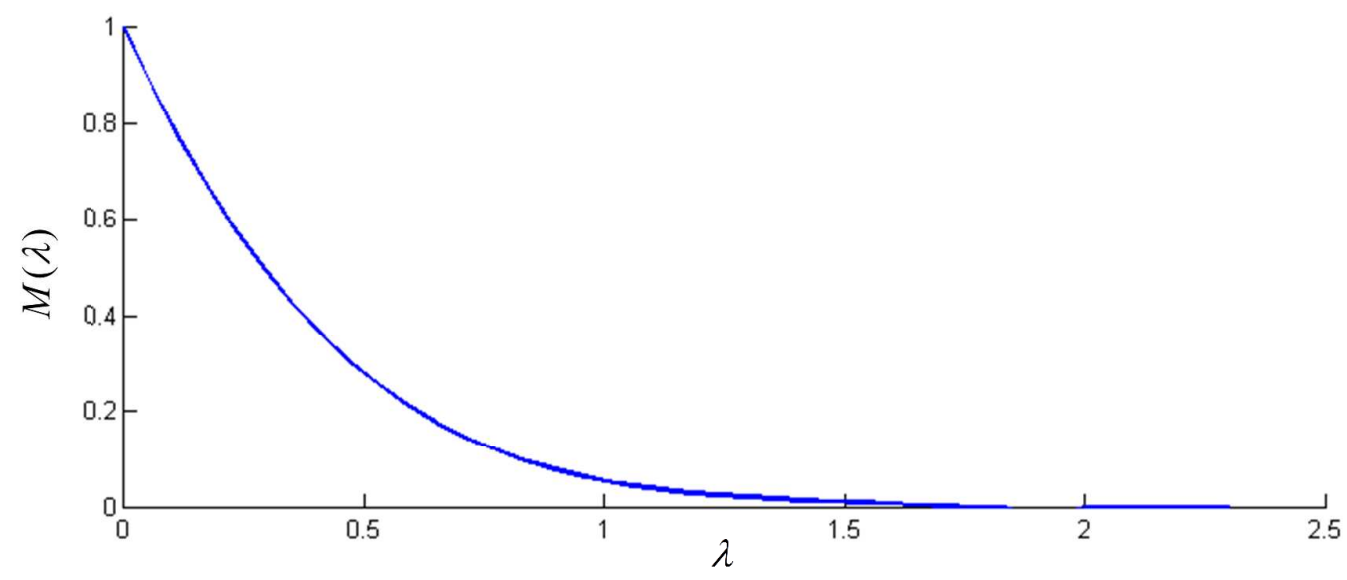

Figure 2. The curve of $M(\lambda)$ 


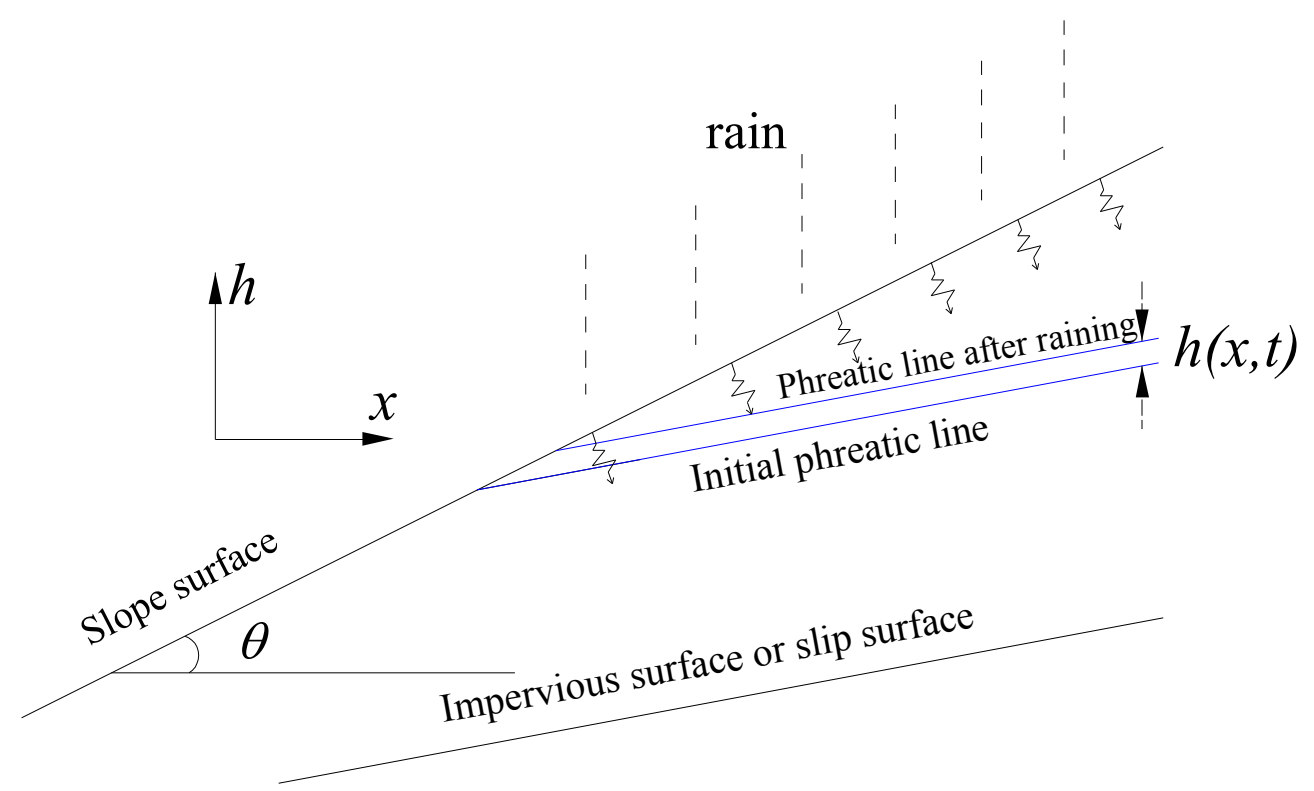

Figure 3. Slope model with an indication of the steady-state groundwater level, the groundwater level change owing to rain infiltration, $h(x, t)$, and the slip surface (modified from Conte and

Troncone 2016) 


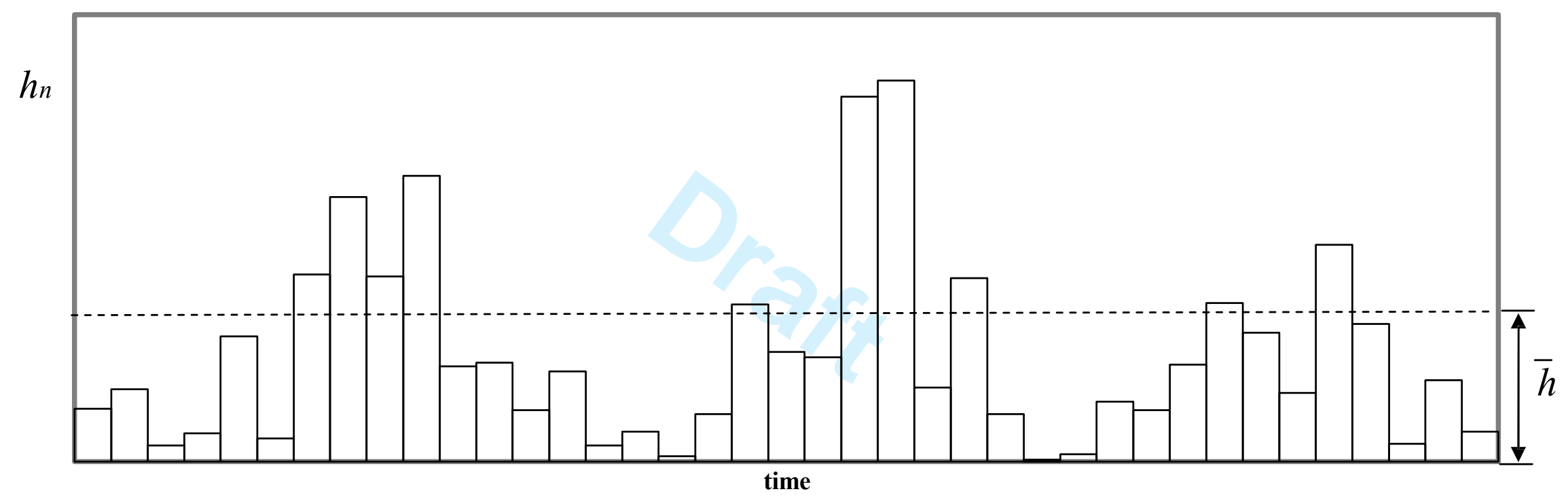

Figure 4. Rain depth, $h_{n}$, and potential rain infiltration depth, $\bar{h}$ (modified from Conte and Troncone 2016). 


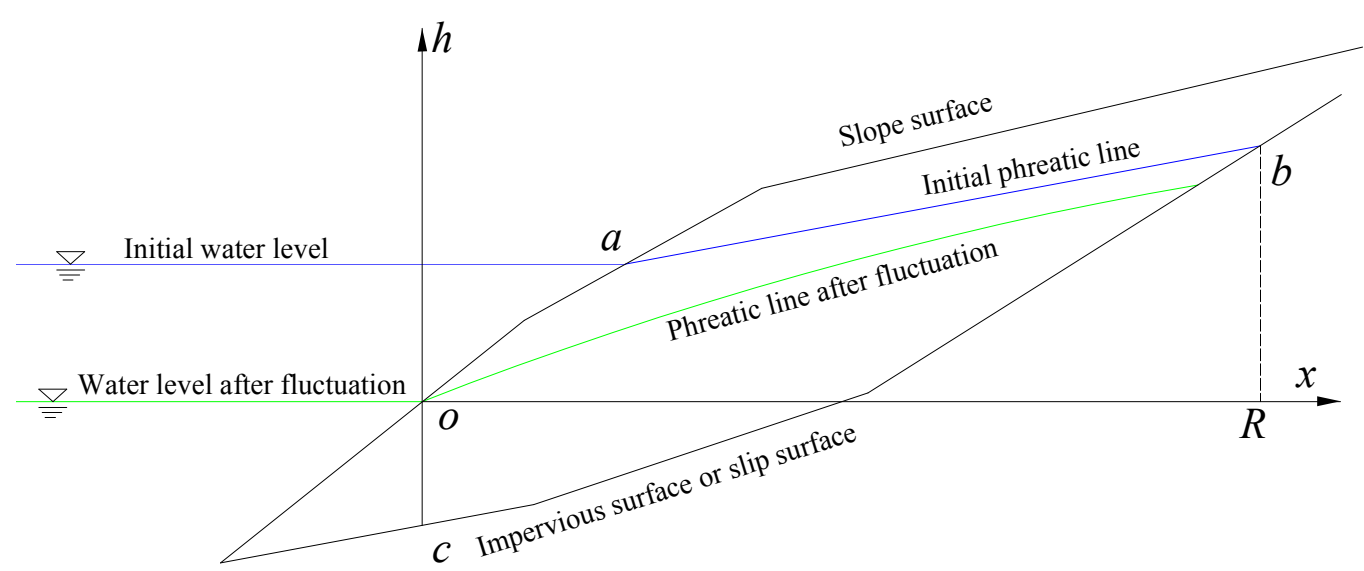

Figure 5. Calculation sketch of aquifer thickness

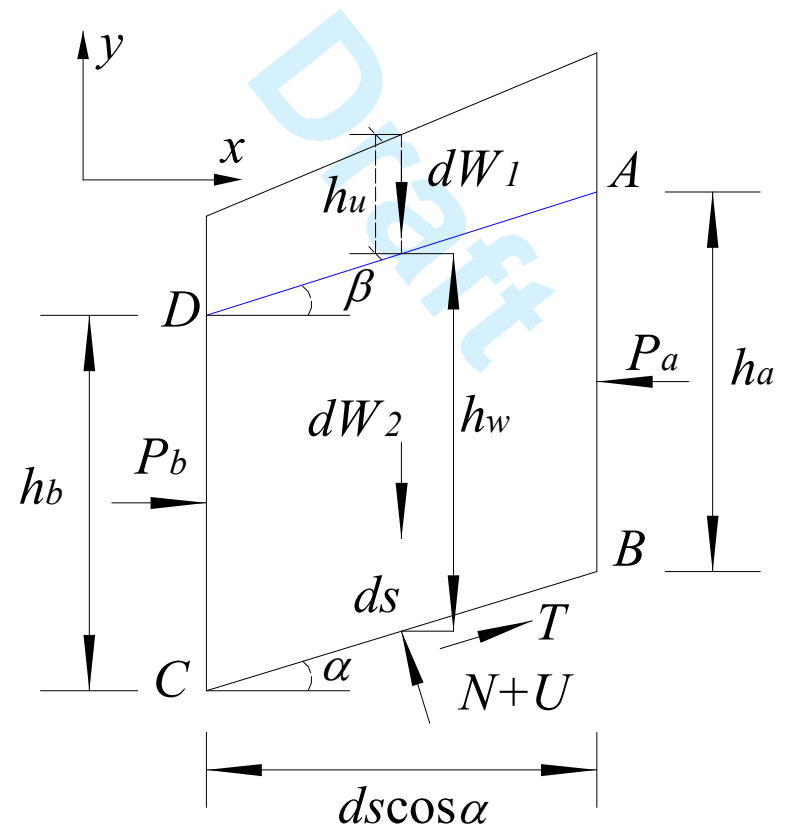

Figure 6. Calculation sketch of differential soil slice 


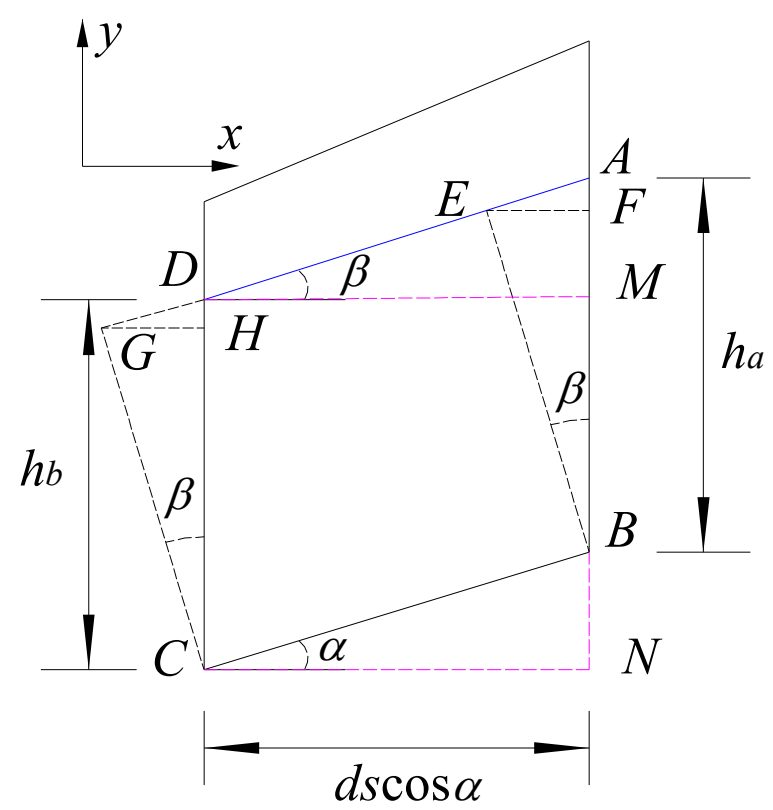

Figure 7. Calculation sketch of hydraulic grade

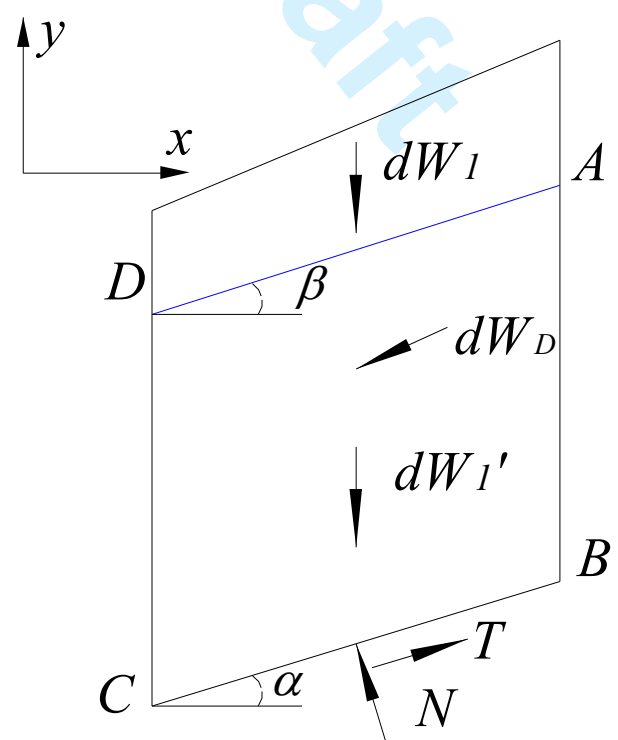

Figure 8. Forces distributing diagrammatic sketch of differential soil slice 


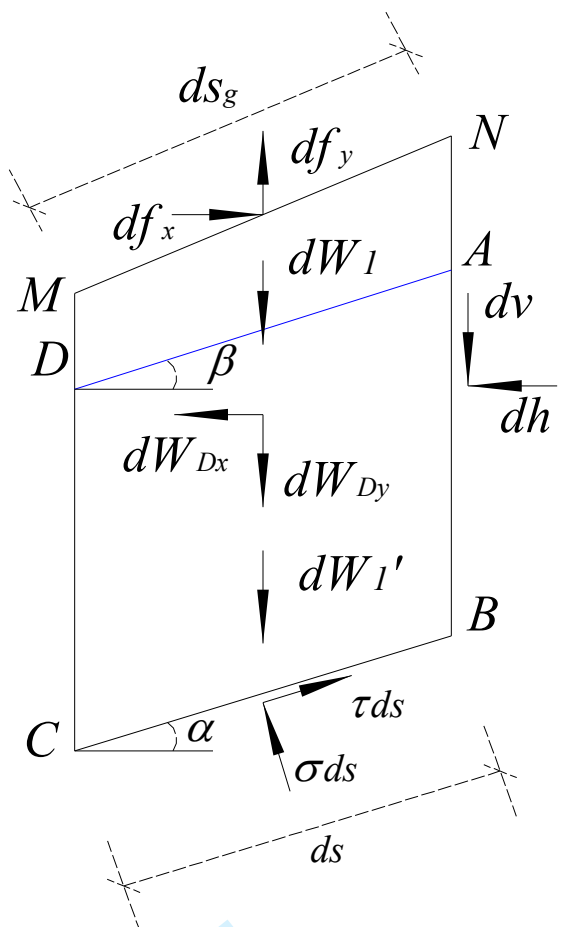

Figure 9. The schematic diagram of a loaded differential slice for derivation of normal stress on sliding surface

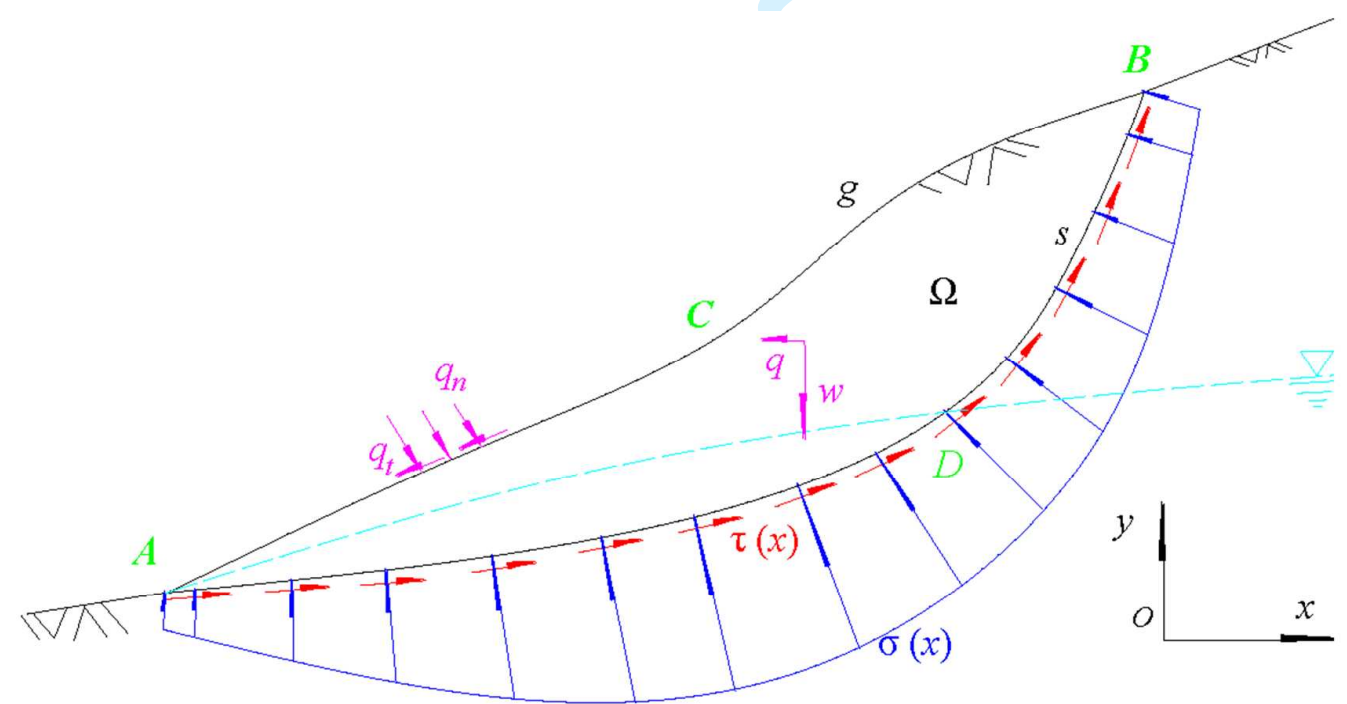

Figure 10. Schematic plot of a sliding body and system of forces on it 


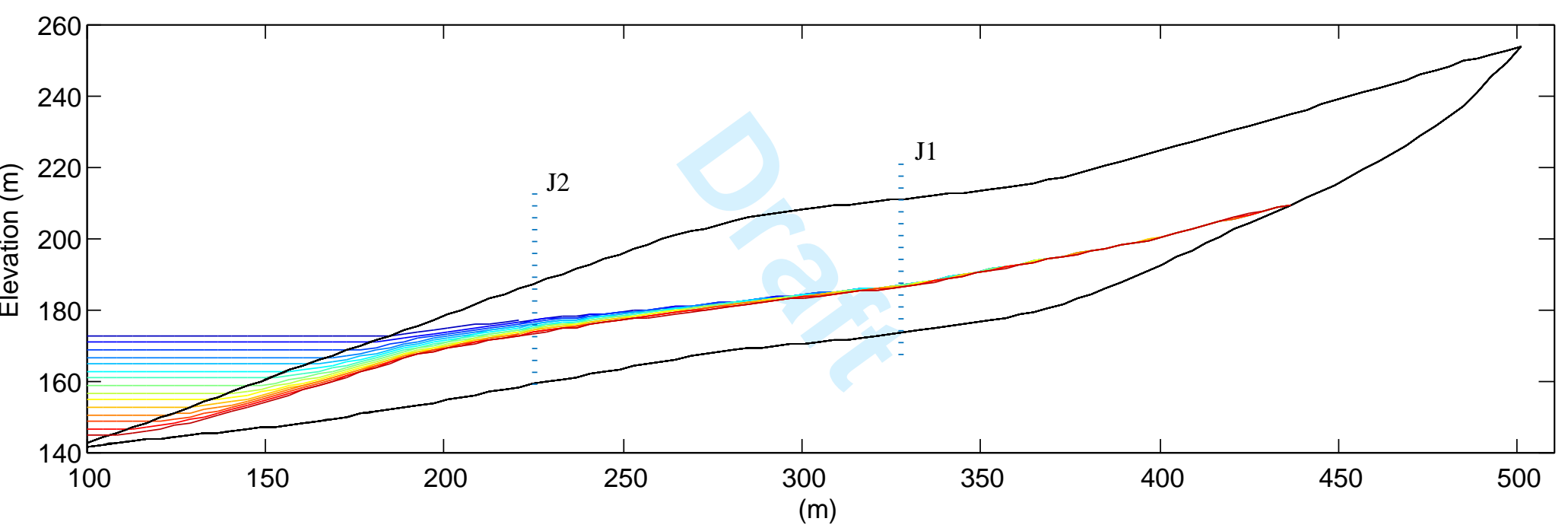

Figure 11. The geological section map and the changes of the underground water level of the verifiable example. 


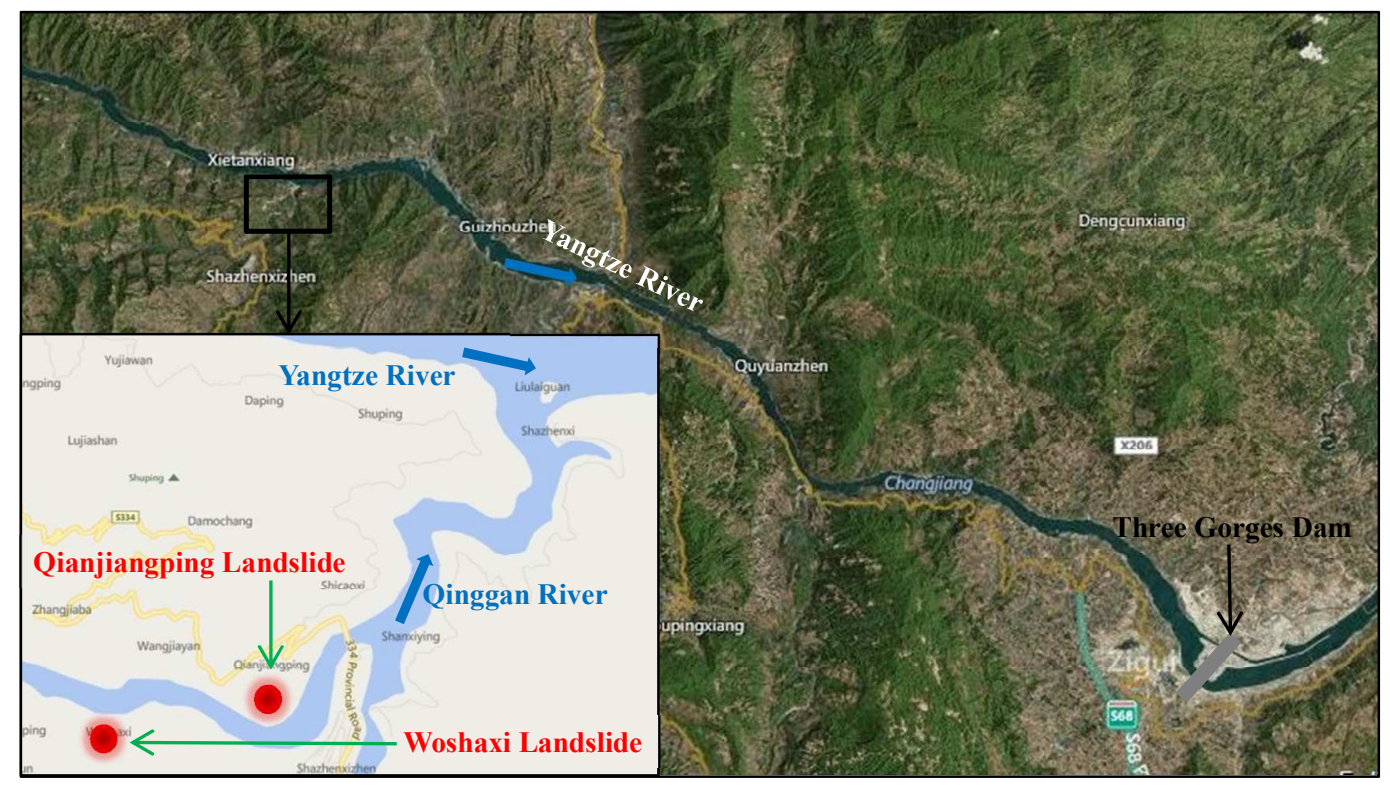

Figure 12. The geographical location map of Woshaxi Slope in the Three Gorges Reservoir

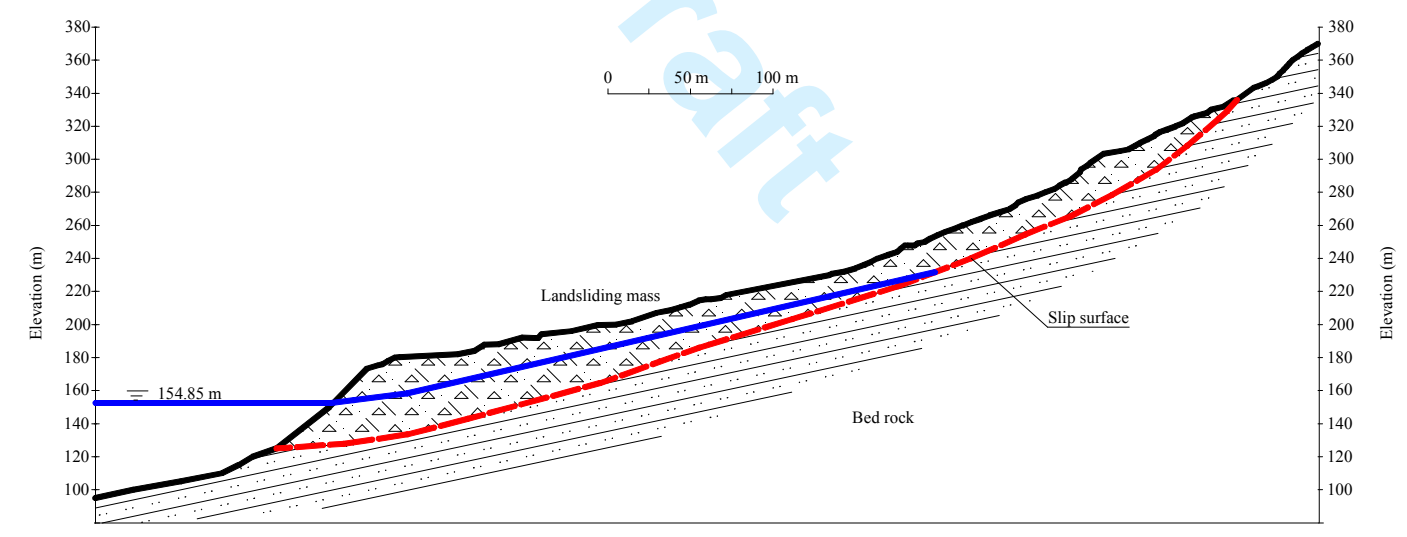

Figure 13. The geological section map of Woshaxi Slope 


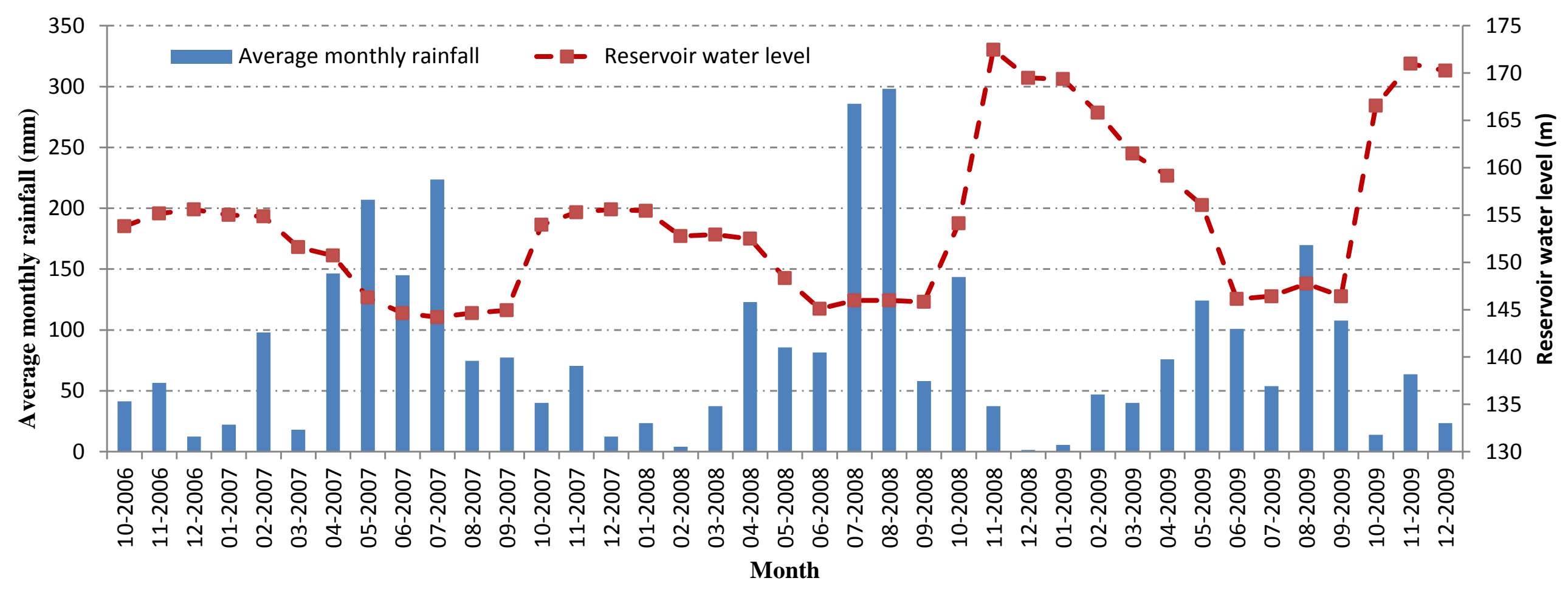

Figure 14. The average monthly rainfall and reservoir water level from 2007 to 2009. 


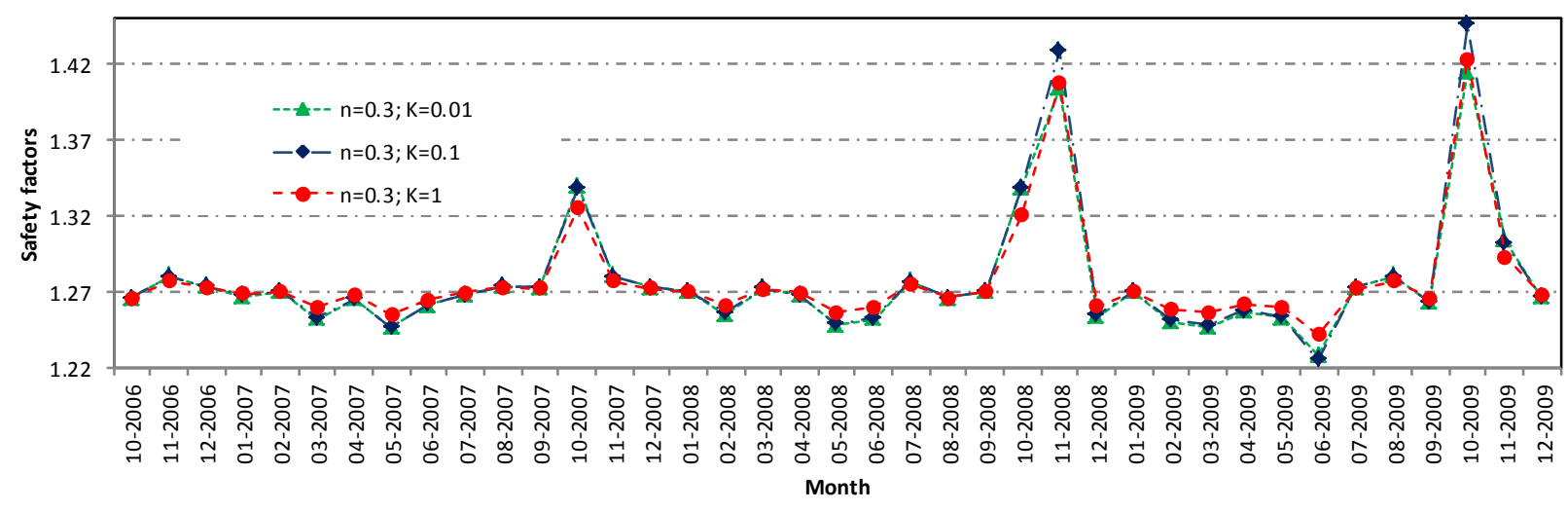

Figure 15. Safety factors of the Woshaxi landslide under the condition of reservoir water level fluctuation from 2007 to 2009 (Different permeability coefficients). 


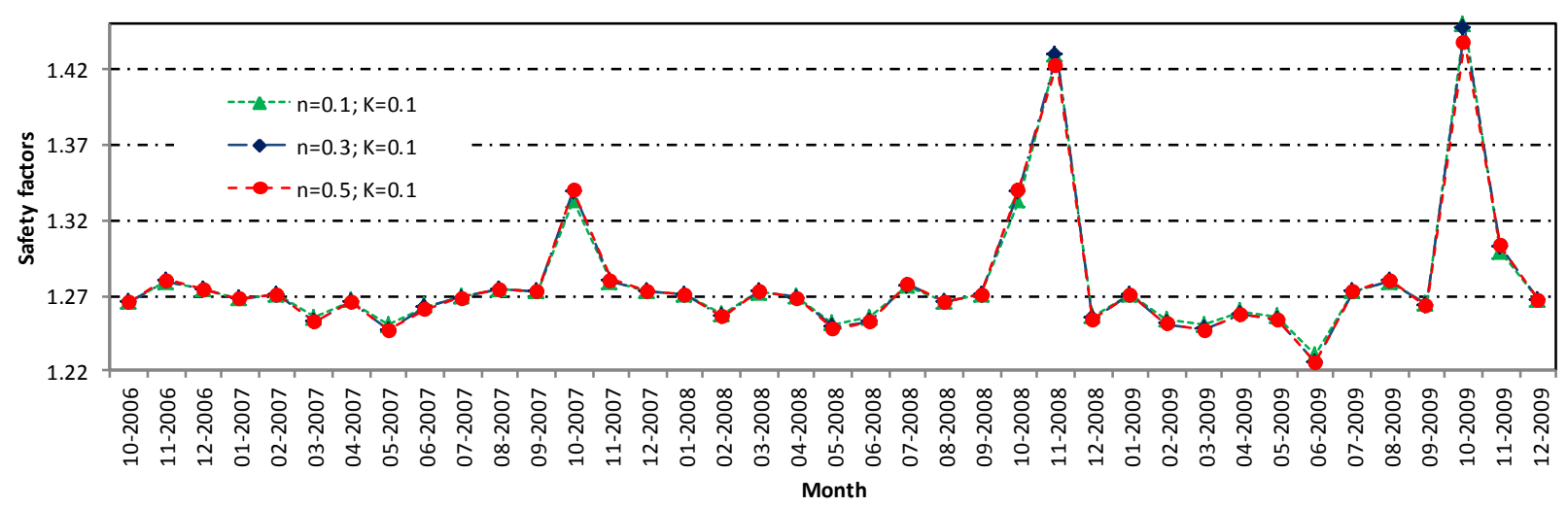

Figure 16. Safety factors of the Woshaxi landslide under the condition of reservoir water level fluctuation from 2007 to 2009 (Different porosity). 


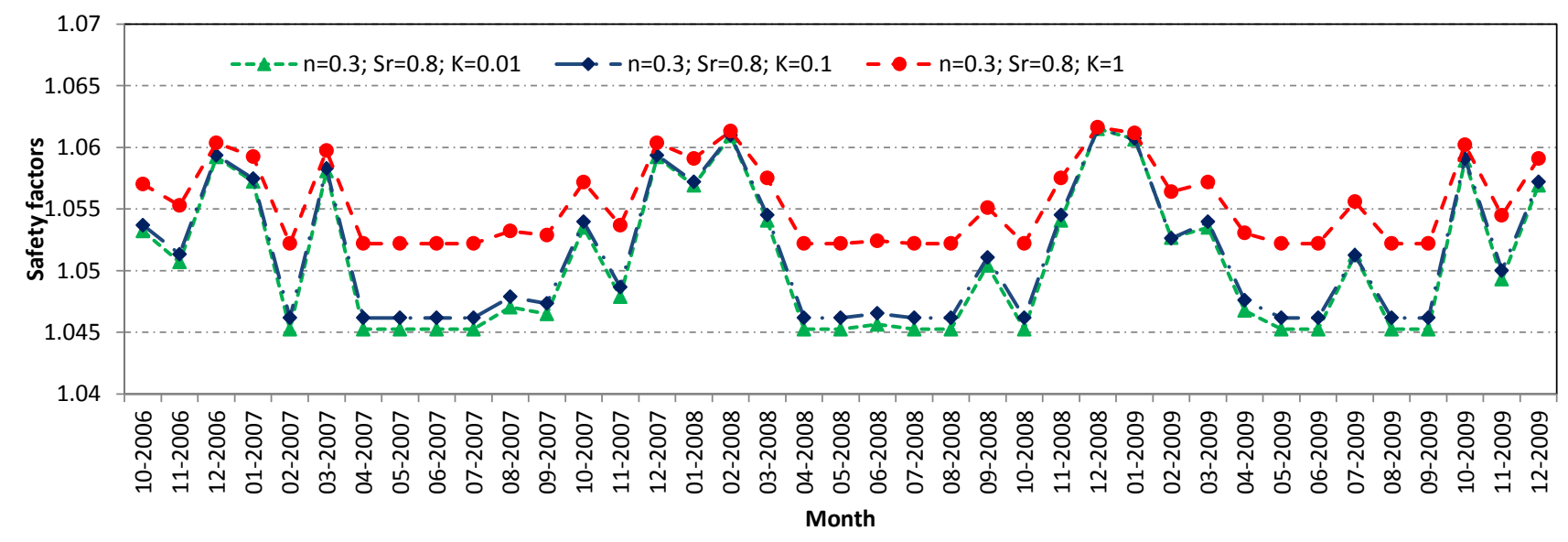

Figure 17. Safety factors of the Woshaxi landslide under the condition of rainfall from 2007 to 2009 (Different permeability coefficients). 


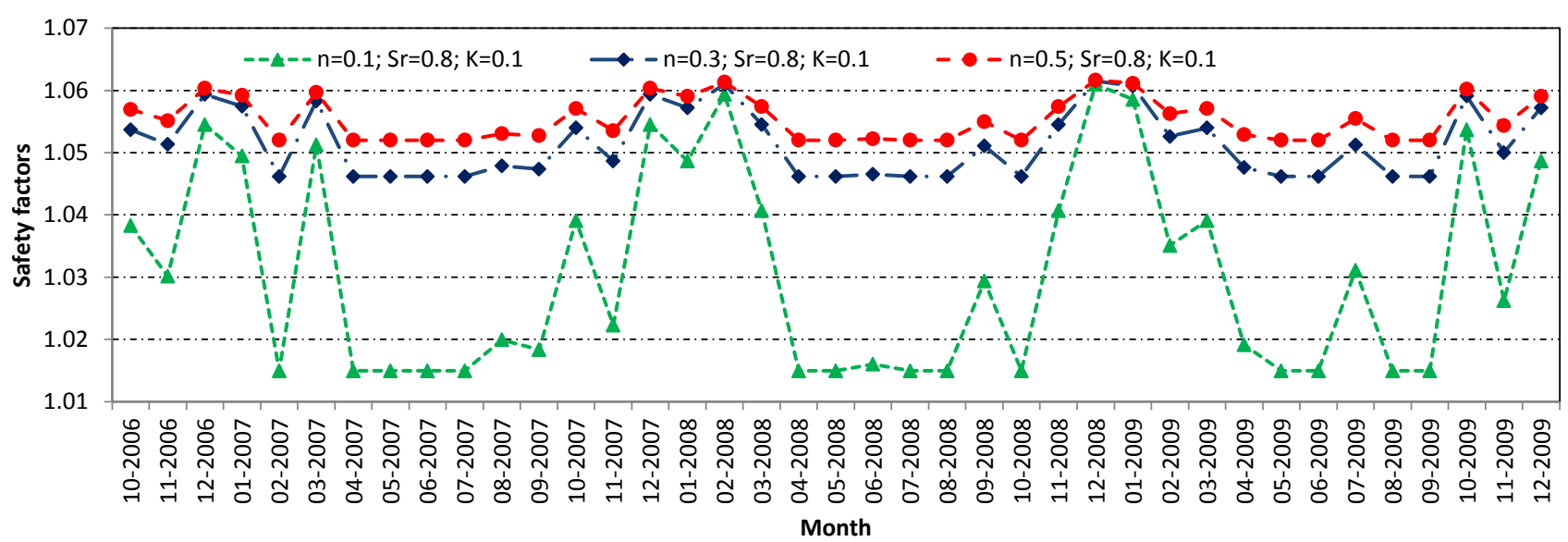

Figure 18. Safety factors of the Woshaxi landslide under the condition of rainfall from 2007 to 2009 (Different porosity). 


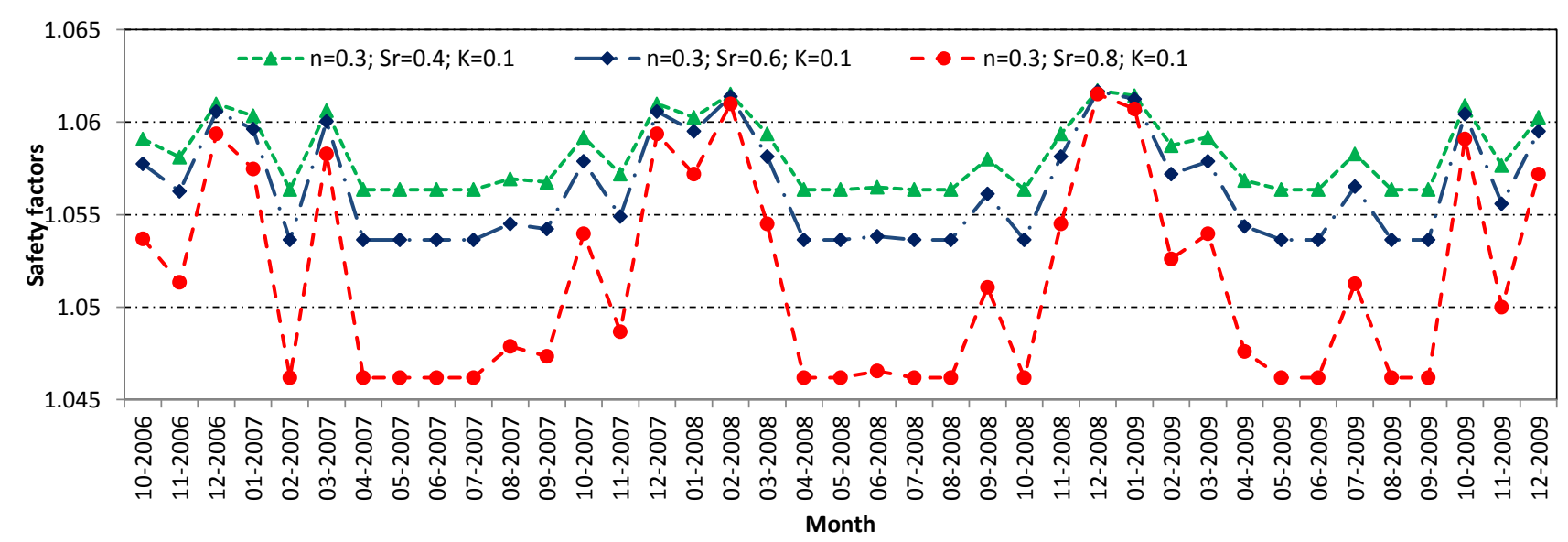

Figure 19. Safety factors of the Woshaxi landslide under the condition of rainfall from 2007 to 2009 (Different saturation). 


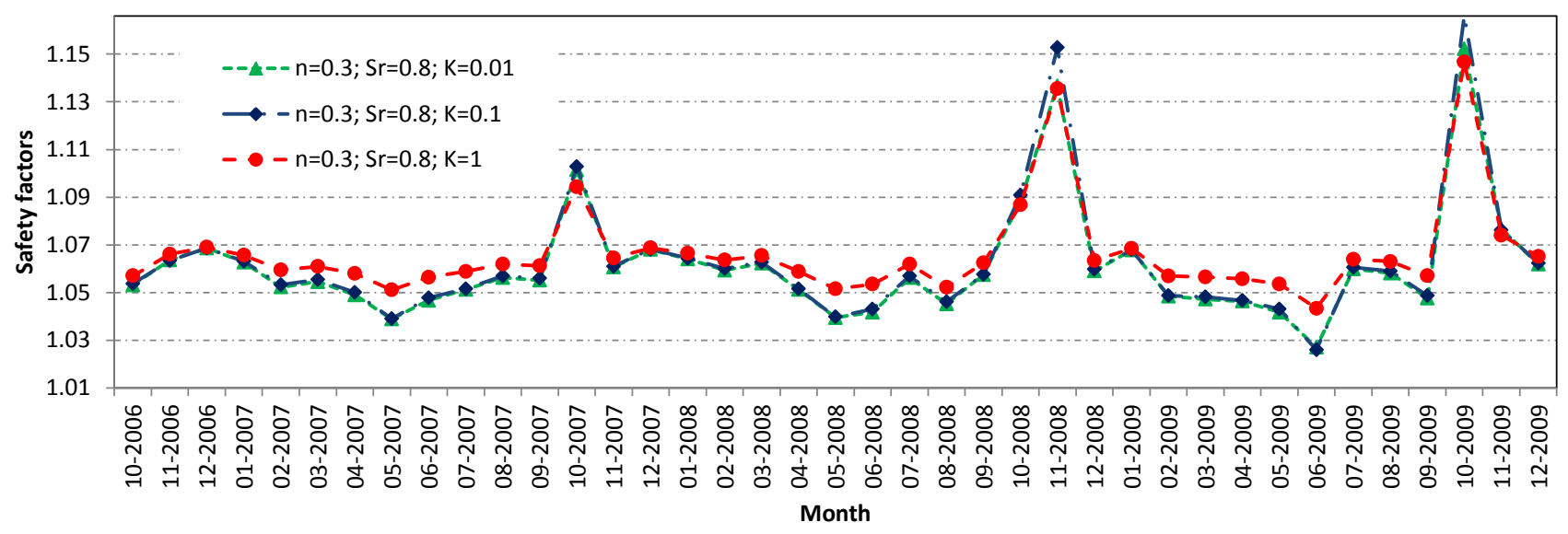

Figure 20. Safety factors of the Woshaxi landslide under the coupling condition of reservoir water level fluctuation and rainfall from 2007 to 2009 (Different permeability coefficients). 


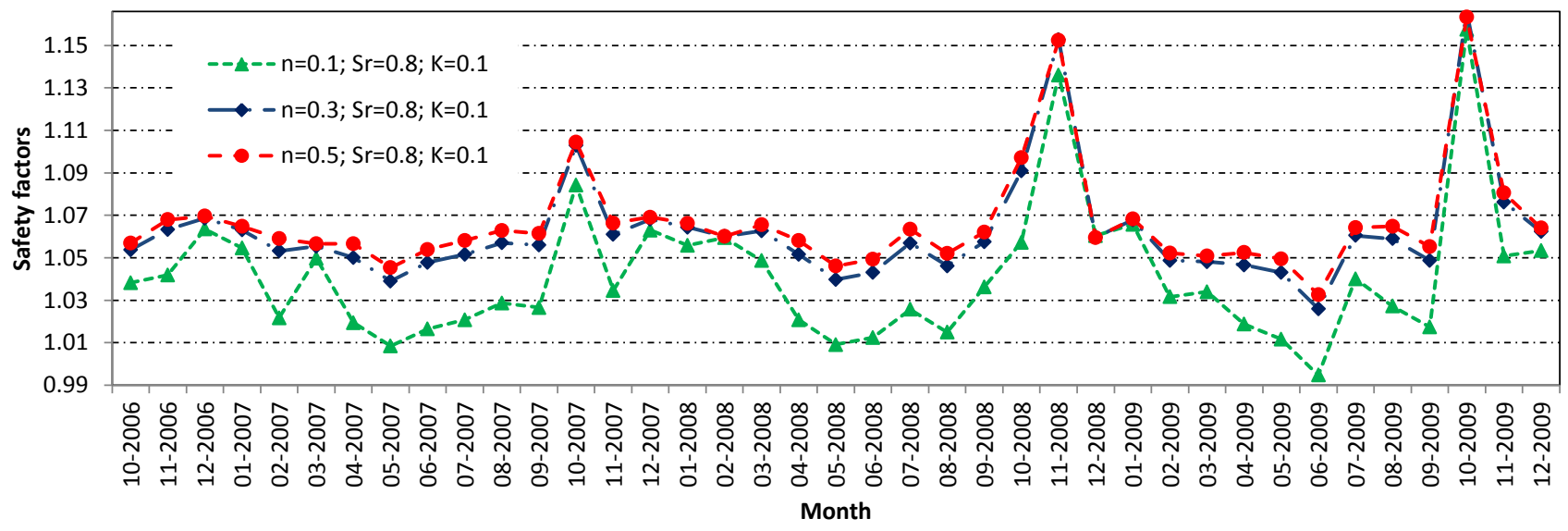

Figure 21. Safety factors of the Woshaxi landslide under the coupling condition of reservoir water level fluctuation and rainfall from 2007 to 2009 (Different porosity). 


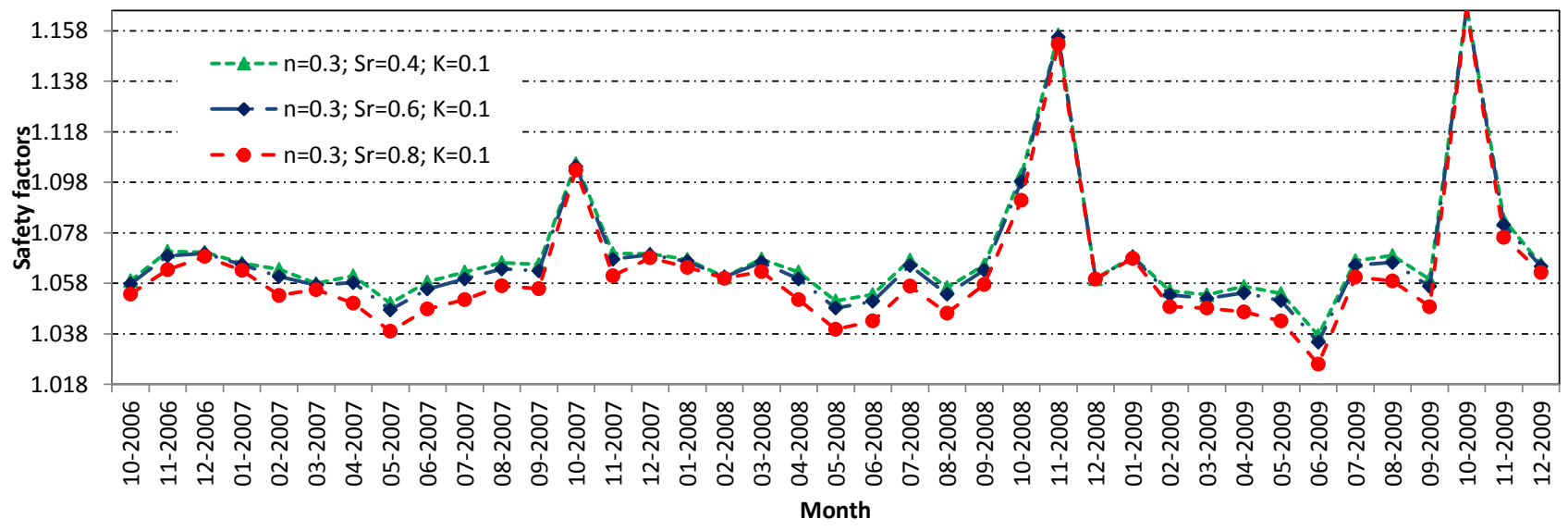

Figure 22. Safety factors of the Woshaxi landslide under the coupling condition of reservoir water level fluctuation and rainfall from 2007 to 2009 (Different saturation). 
Table 1. Parameters of verifiable example

\begin{tabular}{|c|c|c|c|c|c|c|c|c|c|}
\hline \multicolumn{2}{|c|}{$\begin{array}{l}\text { Weight unit } \\
\gamma\left(\mathrm{KN} / \mathrm{m}^{3}\right) \\
\end{array}$} & \multicolumn{4}{|c|}{ Shear strength } & \multirow{3}{*}{$\begin{array}{c}\text { Unconfined aquifer } \\
\text { thickness } \\
H_{m}(\mathrm{~m})\end{array}$} & \multirow{3}{*}{$\begin{array}{c}\text { Permeability coefficient } \\
\mathrm{K} \\
(\mathrm{m} / \mathrm{d})\end{array}$} & \multirow{3}{*}{$\begin{array}{l}\text { Porosity } \\
\text { n }\end{array}$} & \multirow{3}{*}{$\begin{array}{c}\text { Degree of saturation } \\
\mathrm{Sr}\end{array}$} \\
\hline \multirow[b]{2}{*}{ Sturated condition } & \multirow{2}{*}{ Natural condition } & \multicolumn{2}{|c|}{ Saturated condition } & \multicolumn{2}{|c|}{ Natural conditon } & & & & \\
\hline & & $\begin{array}{c}c_{e} \\
(\mathrm{kPa})\end{array}$ & $\begin{array}{c}\varphi \\
(\circ)\end{array}$ & $\begin{array}{c}c_{e} \\
(\mathrm{kPa})\end{array}$ & $\begin{array}{c}\varphi \\
(\circ)\end{array}$ & & & & \\
\hline 22.8 & 21.1 & 12.8 & 25.8 & 13.5 & 28.9 & 43 & 0.1 & 0.3 & 0.8 \\
\hline
\end{tabular}

Table 2. Parameters of Woshaxi Slope

\begin{tabular}{|c|c|c|c|c|c|c|c|c|c|}
\hline \multicolumn{2}{|c|}{$\begin{array}{l}\text { Weight unit } \\
\gamma\left(\mathrm{KN} / \mathrm{m}^{3}\right) \\
\end{array}$} & \multicolumn{4}{|c|}{ Shear strength } & \multirow{3}{*}{$\begin{array}{c}\text { Unconfined aquifer thickness } \\
H_{m}(\mathrm{~m})\end{array}$} & \multirow{3}{*}{$\begin{array}{c}\text { Permeability coefficient } \\
\text { K } \\
(\mathrm{m} / \mathrm{d})\end{array}$} & \multirow{3}{*}{$\begin{array}{l}\text { Porosity } \\
\quad \mathrm{n}\end{array}$} & \multirow{3}{*}{$\begin{array}{l}\text { Degree of saturation } \\
\mathrm{Sr}\end{array}$} \\
\hline \multirow[b]{2}{*}{ Sturated condition } & \multirow{2}{*}{ Natural condition } & \multicolumn{2}{|c|}{ Saturated condition } & \multicolumn{2}{|c|}{ Natural conditon } & & & & \\
\hline & & $\begin{array}{c}c_{e} \\
(\mathrm{kPa})\end{array}$ & $\begin{array}{c}\varphi \\
(\circ)\end{array}$ & $\begin{array}{c}c_{e} \\
(\mathrm{kPa})\end{array}$ & $\begin{array}{c}\varphi \\
(\circ)\end{array}$ & & & & \\
\hline \multirow{3}{*}{22.4} & \multirow{3}{*}{20.8} & \multirow{3}{*}{18} & \multirow{3}{*}{0.10} & \multirow{3}{*}{22} & \multirow{3}{*}{20} & \multirow{3}{*}{65} & $0.01 / 0.10 / 1.00$ & 0.3 & 0.8 \\
\hline & & & & & & & 0.1 & $0.1 / 0.3 / 0.5$ & 0.8 \\
\hline & & & & & & & 0.1 & 0.3 & $0.4 / 0.6 / 0.8$ \\
\hline
\end{tabular}

